\title{
GCU
}

Glasgow Caledonian

University

University for the Common Good

\section{Plant-Best: a novel plant selection tool for slope protection}

Gonzalez-Ollauri, Alejandro; Mickovski, Slobodan B.

Published in:

Ecological Engineering

DOI:

10.1016/j.ecoleng.2017.04.066

Publication date:

2017

Document Version

Author accepted manuscript

Link to publication in ResearchOnline

Citation for published version (Harvard):

Gonzalez-Ollauri, A \& Mickovski, SB 2017, 'Plant-Best: a novel plant selection tool for slope protection', Ecological Engineering, vol. 106, no. A, pp. 154-173. https://doi.org/10.1016/j.ecoleng.2017.04.066

\section{General rights}

Copyright and moral rights for the publications made accessible in the public portal are retained by the authors and/or other copyright owners and it is a condition of accessing publications that users recognise and abide by the legal requirements associated with these rights.

Take down policy

If you believe that this document breaches copyright please view our takedown policy at https://edshare.gcu.ac.uk/id/eprint/5179 for details of how to contact us. 


\section{Plant-Best: A novel plant selection tool for slope protection}

2 Alejandro Gonzalez-Ollauri ${ }^{1,2}$ and Slobodan B. Mickovski ${ }^{1}$

$3{ }^{1}$ School of Engineering and Built Environment, Glasgow Caledonian University

4 Cowcaddens Road, G4 0BA Glasgow, UK

$5 \quad{ }^{2}$ Corresponding author: alejandro.ollauri@gcu.ac.uk ; gollauri@gmail.com 


\begin{abstract}
6 Abstract
7 Plant-Best is a novel tool for the selection of the most suitable plant cover against rainfall-induced

8 shallow landslides. It explores the plant-derived likelihood of slope failure reduction under wetting and

9 drying events, respectively. Plant-Best comprises five comprehensive open-source modules built in the

10 freeware R. The modules' objectives range from the spatial detection of landslide-prone zones to the

11 integrated evaluation of plant-derived hydro-mechanical effects on sloped terrain; from the selection of

12 the best performing plant species to the identification of sensitive plant traits. In this paper, we provide

13 a detailed description of the Plant-Best modules and we show how this holistic tool can be effectively

14 employed for plant cover selection in a shallow landslide context. To do so, we demonstrate the

15 application of Plant-Best on a site with a history of slope failures in Northeast Scotland, where the tool

16 is implemented using seven native plant species including both woody and herbaceous vegetation. The

17 results reveal that different plant species were suitable for protection depending on the hydrological

18 conditions - i.e. wetting or drying. Plant effects were limited to the topmost soil and, in general,

19 underweight plants with dense root systems and broad thick canopies offered the best resistance to

20 failure. This suggested that botanically diverse slopes with different plant functional groups are

21 desirable for a more effective slope protection. Plant-Best proved to be a relatively simple but robust

22 tool for the detection of landslide-prone zones, the selection and evaluation of plant covers, and the

23 identification of relevant plant traits related to shallow landslides mitigation. The open-source nature of

24 the tool confers a great versatility and applicability to the tool which can be deployed as a multi-

25 disciplinary aid to the decision making process.
\end{abstract}

27 Keywords: Plant selection, landslide, eco-hydrological model, GIS, soil bioengineering, forestry,

28 landscaping, slope protection, $\mathrm{R}$

29 
Soil loss is a global natural threat to the integrity and function of the Earth's ecosystems (EEA, 2012; Schwilch et al., 2016). In particular, rainfall-induced landslides have been acknowledged as one of the main drivers of soil loss globally (Sidle and Bogaard, 2016). Landslides severity and recurrence will likely increase under the predicted intensification of the hydrological cycle due to climate change (Roderick et al., 2014; Gariano and Guzzetti, 2016), creating an urgent need to take action against potential soil mass wasting. The existing body of studies focusing on the prediction of landslides timing and location is broad and it is still growing (Sidle and Bogaard, 2016). Landslides prediction has commonly been based on the establishment of rainfall triggering thresholds on steep areas (Gariano et al., 2015) and on the use of spatial algorithms able to include terrain features (slope, aspect, curvature) as predictors of landslides (e.g. Vorpahl et al., 2012). Landslide prediction outcomes are normally employed for mapping and establishing landslide hazards, which are then used to estimate landslidederived risks (e.g. life and property losses, infrastructure damages; van Westen et al., 2006). However, tools and research aiming at evaluating what prevents rather than what triggers landslides, although topical, still need further development.

The sustainable use of plants for soil protection has been widely accepted (see Norris et al., 2008 and Stokes et al., 2014 for review). It has been demonstrated that plants are able to provide mechanical and hydrological reinforcement to sloped soils (Gonzalez-Ollauri and Mickovski, 2017a, 2017c) additional to the enhanced biodiversity (Gonzalez-Ollauri and Mickovski, 2017b). The existing research on the topic has led to numerical models that aim at quantifying the potential of vegetation for landslide mitigation (e.g. see $\mathrm{Wu}, 2015$ for review). Most of these models tend to include the mechanical soil reinforcement provided by vegetation roots by using information related to the root spread in the soil and the root material strength (Stokes et al., 2009). However, there are issues that the existing models do not address. On the one hand, the hydrological effect of vegetation against landslides, albeit commonly discussed, is poorly understood and quantified (Stokes et al., 2014). In fact, the inclusion of the hydrological effects of vegetation within slope stability analyses still remains challenging (Gonzalez-Ollauri and Mickovski, 2017c). Additionally, there are plant-related processes that could be detrimental for slope stability and, yet they are usually neglected. For example, woody plants tend to concentrate large volumes of rainwater around the stem (i.e. stemflow; Levia and Germer, 2015). It has been observed that stemflow may make its way into the soil through the root cavities as a bypass flow (Liang et al., 2011). This type of water flow may provoke dramatic changes in the soil stress-state condition (Lu and Godt, 2013) or result in formation of perched water tables (Liang et al., 2011), both with negative effects on slope stability. On the other hand, vegetated slope stability models tend to focus on the landslide triggering mechanisms (e.g. tRIBS+VEGGIE; Ivanov et al., 2008a, 2008b) without paying much attention to what particular plant traits may be relevant for effective landslide prevention. For example, the size, thickness and morphology of the plant canopy may affect the water balance above and below the ground (Levia and Germer, 2015). The stem size can indicate the plant aboveground biomass (Zinais et al., 2005) and, in turn, the root spread in the soil 
allometric relationship between the above- and belowground plant parts (Cheng and Niklas, 2007) together with a function portraying the root distribution in the soil (e.g. Preti et al., 2010).

From a practical perspective, the existing slope stability models accounting for vegetation effects cannot be used for plant-species selection. Ideally, a plant selection tool for evaluating the soil reinforcement ability of different species should combine easily measurable plant traits with a sound geotechnical basis (Mickovski et al 2006; Stokes et al., 2009), while the environmental variability at the plant, soil, and climate compartments is also considered. To the best of our knowledge, such a tool does not yet exist.

84 Geotechnical engineers, foresters, landscape architects, land planners or restoration ecologists would benefit from an effective decision-support tool for plant selection against landslides once an ecological evaluation of the candidate plants has been carried out (Evette et al., 2012; Jones, 2013). Such a tool will permit to foresee long-term effects produced by different plant covers on slopes, the results of combining plant functional groups in restoration actions, or the responses under different soil and climate scenarios. As a result, an effective plant selection tool will contribute to make soil bioengineering decisions more reliable and effective, ensuring the success of ecological restoration actions on slopes.

The aim of this paper is to introduce Plant-Best, a novel tool for selection of the most suitable plant cover against rainfall-induced shallow landslides. In the present paper we provide a step-by-step description of the Plant-Best workflow and we show how this holistic tool can be employed for an effective plant cover selection in a shallow landslide or a slope protection context. To do so, Plant-Best is applied on a site with a history of slope failures in Northeast Scotland and it is implemented using seven native plant species.

\section{MATERIALS AND METHODS}

\subsection{Plant-Best overview}

Plant-Best is an open-source, computer-based tool for the selection of the most suitable plant species against rainfall-induced shallow landslides. It explores the plant-derived likelihood reduction of slope failure under wetting and drying episodes, respectively. The tool combines five major modules (Fig. 1). The first module (I, Section 2.2) detects landslide-prone zones or zones for slope restoration through a GIS-based model approach needing a digital surface model (DSM) as an input. The second module (II, Section 2.3) consists of a distributed eco-hydrological process-based model (Gonzalez-

108 Ollauri and Mickovski, 2014) that combines the hydrological and mechanical effects of vegetation on slope stability. This module employs the model inputs generated within the two subsequent modules

110 (i.e. III and IV) to compute pixel-based slope stability under different soil-plant covers and

111 hydrological conditions at user-defined soil depths. The third (Section 2.4) and fourth (Section 2.5)

112 modules generate fixed and stochastic model inputs, respectively. The former generates spatially

113 explicit soil variables through the implementation of a machine-learning algorithm (i.e. Random

114 Forest; Breimar et al., 2002). The latter uses the Monte Carlo method (e.g. Ross, 2006) on readily

115 measurable and available plant-soil-climate information to account for environmental variability. 
116 Eventually, the fifth module (V, Section 2.6) manages uncertainty by calculating a reliability index 117 (Malkawi et al., 2000), performs a series of statistical tests to identify the most suitable plant species, and carries out a sensitivity analysis for the identification of relevant plant traits.

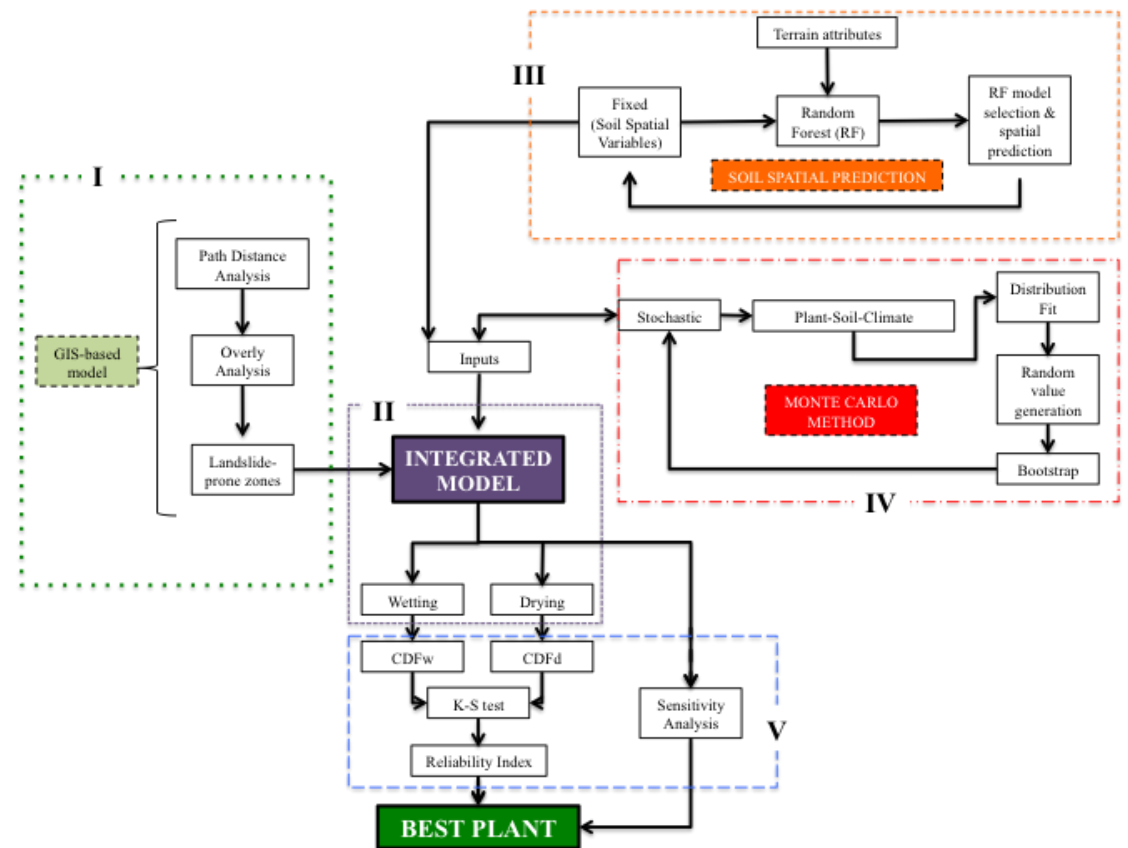

131 Figure 1. Plant-Best flowchart showing the tool workflow, different modules, and their interconnections. I: Landslide-prone zones detection module. II: Integrated model module. III: fixed soil spatial variables generation module. IV: Stochastic input variables generation module. V: statistical and sensitivity analysis module.

2.2. Module I: Landslide-prone zones detector

This module combines GIS-based path distance and overlay analyses (e.g. Zhu, 2016), and it is envisaged as a first approximation in the detection of zones prone to slope instability. For a better illustration of how this module works, the series of required GIS-based tasks (Fig. 2) were carried out in ESRI ArcGIS 10.

Landslide-prone zones are assumed to occur on steep zones (slope gradient $>20^{\circ}$; e.g. Cimini et al., 2015) located within two water accumulation areas (e.g. Wilkinson et al., 2002). The water accumulation areas within the study site can be detected with the path distance analysis, which ultimately estimates the cartographic depth-to-water index ( $\mathrm{D}_{\mathrm{Tw}}$; White et al., 2012). To proceed with the path distance analysis, a flow accumulation raster, a slope raster, and a digital surface model (DSM;

$1442 \times 2$ m; GetMapping, 2014) can be employed as source, cost, and surface raster, respectively (Fig. 2). The flow accumulation and slope rasters can be obtained from the implementation of ArcGIS Spatial

146 Analyst functions using the DSM as unique input into this module. The output from the path distance 147 analysis can then be multiplied by the DSM resolution (i.e. $2 ; 2 \times 2 \mathrm{~m}: 4 \mathrm{~m}^{2}$ ) to obtain $\mathrm{D}_{\mathrm{Tw}}$ (White et al., 148 2012). Subsequently, the areas of water accumulation can be buffered depending on the site scale (e.g.

$14950 \mathrm{~m}$ in our case) and overlaid with the slope attribute, to which a high weight should be arbitrarily 150 given - e.g. buffer +5 *slope, as slope failures most likely occur on steeper terrain (Lu and Godt, 2013).

151 Eventually, those pixels falling within the overlay output and presenting a slope gradient above $20^{\circ}$ can 152 be extracted to obtain the landslide-prone zones raster. 


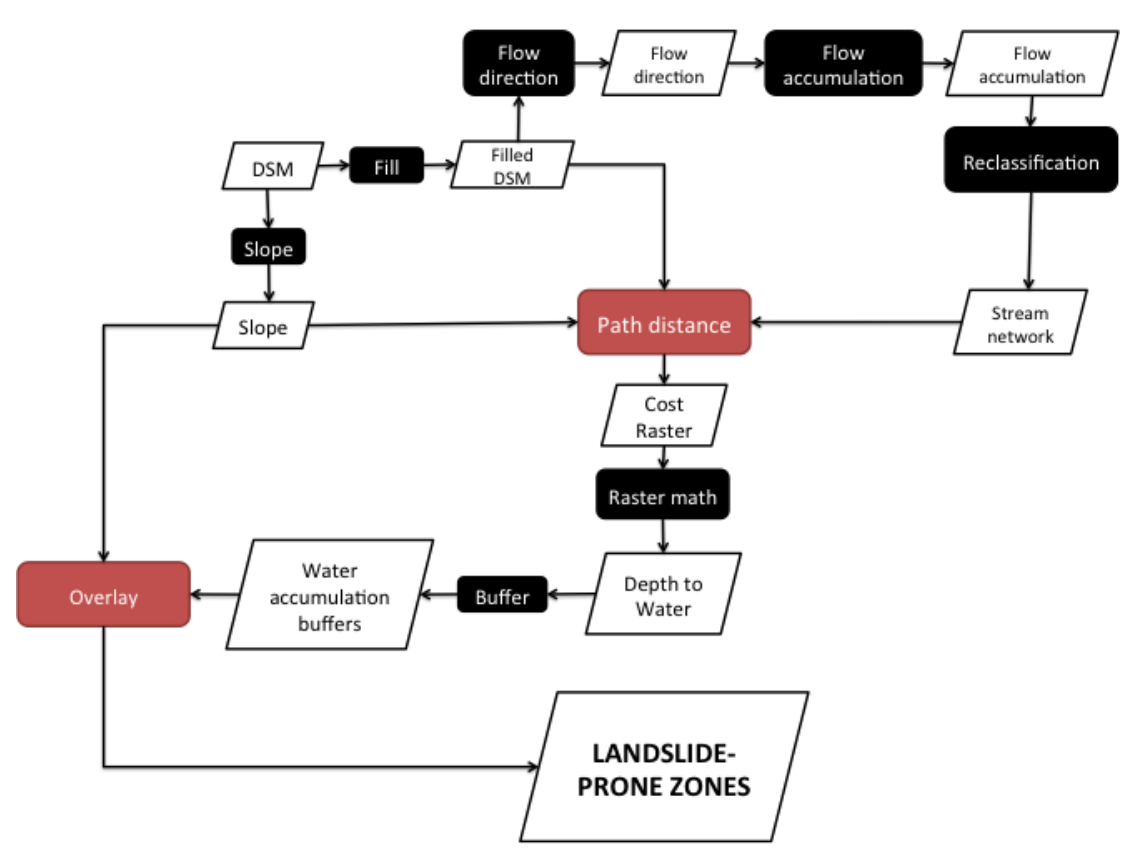

169

(b)

173

174

Figure 2. Module I: Landslide-prone zones detection module summary flowchart showing the implied GIS-based tasks. Trapezium boxes stand for GIS layers. Oval boxes stand for GIS tasks. The arrows indicate the flow of tasks.

Figure 3. a) Module II: Conceptual model belonging to the Integrated model for the hydro-mechanical effect of vegetation against shallow landslides (Gonzalez-Ollauri and Mickovski, 2014, 2017c). b) Flowchart summarising the model's workflow.

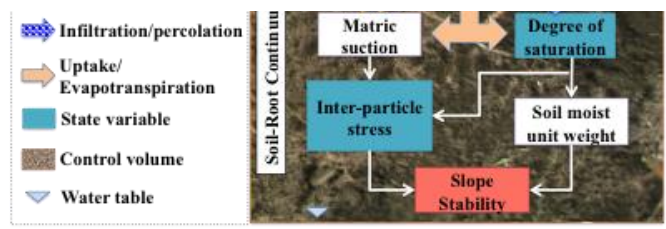

Plant-Best implements a freeware-based (R v. 3.2.1; R Core Team, 2015),
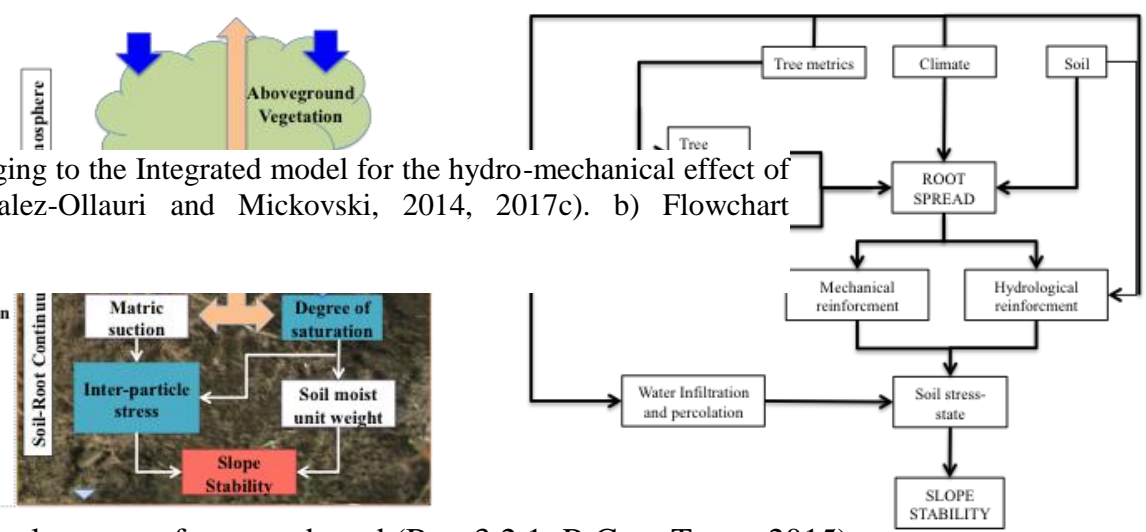
spatially-upgraded version of an integrated, process-based, eco-hydrological model designed to quantify the hydro-mechanical effect of vegetation on sloped soil (Fig. 3; Gonzalez-Ollauri and Mickovski, 2014, 2015, 2017c). The model equations and assumptions are listed in Appendices A and $\mathrm{B}$, respectively. The model code is provided within the supplementary materials. The required inputs to operate the model are shown in Table 1. These inputs belong to the plant, soil, and climate compartments, respectively. The model inputs are processed by Modules III and IV depending on the input typology - i.e. F: fixed or S: stochastic (Table 1; Fig. 1). The inputs values employed in this study are shown in Tables 3 and 4. 
Table 1. List of input parameters/variables belonging to the plant, soil and climate compartments used to operate Plant-Best. S: Stochastic; F: Fixed

\begin{tabular}{|c|c|c|c|c|}
\hline Compartment & Parameter/Variable & Symbol & Units & Type \\
\hline \multirow[t]{12}{*}{ Plant } & Tree-crown area & $A c$ & $\mathrm{~m}^{2}$ & $\mathrm{~S}$ \\
\hline & Diameter at breast height & $\mathrm{DBH}$ & $\mathrm{m}$ & $\mathrm{S}$ \\
\hline & Aboveground biomass per unit area & $M a$ & $\mathrm{~g} \mathrm{~m}^{-2}$ & $S$ \\
\hline & Allometric power-law parameter & $\alpha_{a}$ & unitless & $\mathrm{S}$ \\
\hline & Allometric scaling parameter & $\beta_{a}$ & unitless & $\mathrm{S}$ \\
\hline & Root mass density & $\rho_{r}$ & $\mathrm{~g} \mathrm{~cm}^{-3}$ & $\mathrm{~S}$ \\
\hline & Mean root tensile strength & $\operatorname{Tr}$ & $\mathrm{kPa}$ & $\mathrm{S}$ \\
\hline & Canopy storage capacity & Sc & $\mathrm{mm} \mathrm{m}^{-2}$ & $\mathrm{~S}$ \\
\hline & Stemflow regression line intercept & $a_{s}$ & unitless & $\mathrm{S}$ \\
\hline & Stemflow regression line slope & $b_{s}$ & unitless & $\mathrm{S}$ \\
\hline & Leaf area index & $L A I$ & $\mathrm{~m}^{2} \mathrm{~m}^{-2}$ & $\mathrm{~S}$ \\
\hline & Light extinction coefficient & $k_{c}$ & $/ 1$ & $\mathrm{~S}$ \\
\hline \multirow[t]{21}{*}{ Soil } & Sand content & $S n$ & $\%$ & $\mathrm{~F}$ \\
\hline & Silt content & $S l$ & $\%$ & $\mathrm{~F}$ \\
\hline & Clay content & $\mathrm{Cl}$ & $\%$ & $\mathrm{~F}$ \\
\hline & Organic matter content & SOM & $\%$ & $\mathrm{~F}$ \\
\hline & Soil porosity & $\Phi$ & $/ l_{1}$ & $\mathrm{~F}$ \\
\hline & Volumetric moisture content at saturation & $\theta_{s}$ & $/ 1$ & $\mathrm{~F}$ \\
\hline & Volumetric moisture content at field capacity & $\theta_{f_{c}}$ & $/ l_{1}$ & $\mathrm{~F}$ \\
\hline & Volumetric moisture content at wilting point & $\theta_{w p}$ & $/ l_{1}$ & $\mathrm{~F}$ \\
\hline & Soil water available to plants & $\Phi\left(\theta_{f_{c-}} \theta_{w p}\right)$ & $/ 1$ & $\mathrm{~F}$ \\
\hline & Saturated hydraulic conductivity & $K s$ & $\mathrm{~m} \mathrm{~s}^{-1}$ & $\mathrm{~F}$ \\
\hline & Hydraulic head of wetting front & $\varphi_{w f}$ & $\mathrm{~m}$ & $\mathrm{~F}$ \\
\hline & Effective cohesion & $c^{\prime}$ & $\mathrm{kPa}$ & $\mathrm{S}$ \\
\hline & Angle of internal friction & $\phi^{\prime}$ & $\circ$ & $\mathrm{S}$ \\
\hline & Inverse air-entry pressure fallow soil & $\alpha$ & $\mathrm{kPa}^{-1}$ & $\mathrm{~S}$ \\
\hline & Inverse air-entry pressure vegetated soil & $\alpha_{v}$ & $\mathrm{kPa}^{-1}$ & $\mathrm{~S}$ \\
\hline & Pore-size distribution parameter fallow soil & $n$ & unitless & $\mathrm{S}$ \\
\hline & Pore-size distribution parameter vegetated soil & $n_{v}$ & unitless & $\mathrm{S}$ \\
\hline & Specific gravity of soil & Gs & unitless & $\mathrm{F}$ \\
\hline & Unit weight of water & $\gamma_{w}$ & $\mathrm{kPa} \mathrm{m}^{-1}$ & $\mathrm{~F}$ \\
\hline & Soil depth; vertical coordinate upward positive & $z$ & $\mathrm{~m}$ & $\mathrm{~F}$ \\
\hline & Ground water table height & $H_{w t}$ & $\mathrm{~m}$ & $\mathrm{~F} / \mathrm{S}$ \\
\hline \multirow[t]{5}{*}{ Climate } & Gross rainfall & $P g$ & $\mathrm{~mm}$ & $\mathrm{~S}$ \\
\hline & Rainfall duration & $t r$ & $\mathrm{~h}$ & $\mathrm{~F}$ \\
\hline & Mean rainfall intensity during growing season & $\alpha_{c}$ & $\mathrm{~mm} \mathrm{event}^{-1}$ & $\mathrm{~S}$ \\
\hline & $\begin{array}{l}\text { Frequency of rainfall events during growing } \\
\text { season }\end{array}$ & $\lambda_{c}$ & $/ 1$ & $S$ \\
\hline & Potential daily evapotranspiration rate & $E u$ & $\mathrm{~mm} \mathrm{~d}^{-1} \mathrm{~m}^{-2}$ & $\mathrm{~S}$ \\
\hline
\end{tabular}

The model is set up for daily discrete meteorological events, and its operational control volume is the soil-root continuum (Fig. 3). Two state variables are defined within the control volume: the soil matric suction and the degree of saturation. Both state variables govern the soil stress-state, which is depicted by the suction stress (i.e. inter-particle stress; Lu and Likos, 2004; Lu et al., 2010) on the basis of soil hydro-mechanical properties ( $\alpha$ and n; Tables 1 and 4). Ultimately, the soil stress-state governs the slope stability.

The forcing functions governing the stress-state are portrayed by the fluxes of water entering (i.e. wetting) and exiting (i.e. drying) the control volume, respectively. The water fluxes entering the soil are represented by the effective rainfall (i.e. gross rainfall minus plant canopy interception) 
infiltrating into the soil, and by the stemflow (i.e. rainfall concentrated around the tree stem) bypassing the soil-root zone (Liang et al., 2011). The water fluxes exiting the soil are defined by the plant transpiration. Both types of water fluxes provoke changes in the soil matric suction as the water experiments a downward or upward flow through the soil-pore space (Lu and Griffiths, 2006; Lu and Godt, 2013).

Before the model evaluates the state variables and the slope stability conditions, a series of preliminary steps are carried out (model equations shown in Appendix A):

\subsubsection{Random tree distribution and aboveground biomass}

Firstly, the potential number of trees that can be established on the area to be restored $\left(N_{\text {stems }}\right)$ can be calculated as the ratio of the restoration area to the mean tree-crown area (Ac; Tables 1 and 3 ). Tree age can be user-defined by means of assigning different mean $A c$ values, for instance. Then, the tree stems are randomly distributed over the restoration area with a bootstrap method with replacement (Efron, 1979). Subsequently, the tree metrics diameter at breast height ( $D B H$; Tables 1 and 3) and crown area $(A c)$ are randomly assigned to each stem with the same method. The latter step allows the stand canopies to overlap spatially, but it neglects the potential effect derived from this - i.e. the whole $A c$ of a given tree individual may contribute to the effect derived from a plant-related mechanism in which $A c$ is involved (e.g. rainfall interception, stemflow, transpiration) without interacting with the canopy of neighbour individuals.

Secondly, the aboveground biomass ( $M a$; Tables 1 and 3) of each tree can be calculated on the basis of the randomly assigned $D B H$ using plant species-specific allometric equations (Zianis et al., 2005, Muukkonen and Mäkipää, 2006). For herbaceous covers, however, the former steps are suppressed and the user must define the aboveground biomass per unit area (e.g. Gonzalez-Ollauri and Mickovski, 2016, 2017b).

\subsubsection{Root spread and soil-root mechanical reinforcement}

The root spread $\left(\operatorname{Ar}(z) ; \mathrm{mm}^{2} \mathrm{~m}^{-1}\right)$ within the user-defined soil spatial columns is modelled as a negative exponential function with the soil depth (Preti et al., 2010; Gonzalez-Ollauri and Mickovski, 2016; see Appendix A). Root spread can be predicted as a function of the root biomass and the rooting depth. The former can be derived from the plant aboveground biomass $(M a)$ by considering the above and belowground biomass allometric coefficients $\left(\alpha_{a}\right.$ and $\beta_{a}$; Tables 1 and 3$)$. Rooting depth depends on the soil (i.e. soil water available to plants; $\Phi\left[\theta_{f c}-\theta_{w p}\right]$; Table 1) and climatic features (i.e. mean rainfall intensity and frequency; $\alpha_{c}$ and $\lambda_{c}$; Tables 1 and 4). Thus, it is estimated differently for dry (Preti et al., 2010) and temperate humid climates (Gonzalez-Ollauri and Mickovski, 2016), respectively. It should be noted that with this rooting depth estimation approach, the impact of the soil density on the root spread, implicit in the soil porosity ( $\Phi$; Craig, 2004), is also included (see Gonzalez-Ollauri and Mickovski, 2016). However, other root features linked to the estimation of soilroot reinforcement (e.g. root elongation rate and diameter; Stokes et al., 2009) and, related to the soil 
physical properties, could have been considered (e.g. Dexter, 2004; Popova et al., 2016) if more complex root spread models were required (e.g. topological model; Arnone et al., 2016).

Once the root spread is predicted, it is then distributed over the pixels adjacent to the randomised tree stem pixels (see Section 2.3.1). With this, asymmetric root systems developing on slope environments can be simulated, too (e.g. Tardio et al., 2016). Next, the soil-root mechanical reinforcement (i.e. root apparent cohesion; $c_{R} ; \mathrm{kPa}$ ) can be quantified by using the 'simple perpendicular model' (SPM; Wu et al., 1979), which requires knowledge of the proportion of rooted soil (i.e. root area ratio; $R A R(z)$ ) and the mean root tensile strength (Tr; Tables 1 and 3). SPM was chosen due to its simplicity, reduced amount of input parameters, and observed realistic application (Mickovski et al., 2008). SPM accounts for the reinforcement effect of small, non-structural roots (Mickovski et al., 2009). To avoid potential over predictions of the soil-root reinforcement effect using SPM, a correction factor of 0.4 was included within the model (Preti, 2013). To consider the effect of big structural roots (e.g. sinkers or tap roots), the model code can be modified to accommodate other root reinforcement models (e.g. pull-out model; e.g. Ennos, 1990).

\subsubsection{Aboveground water mass balance: Rainfall interception and stemflow}

The model includes an aboveground water mass balance assessment to estimate the effective rainfall infiltrating the soil $\left(E R ; \mathrm{mm} \mathrm{H}_{2} \mathrm{O} \mathrm{h}^{-1}\right)$ after the gross rainfall $(P g$; Table 1$)$ is intercepted by the canopy (Gonzalez-Ollauri and Mickovski, 2017c). The rainfall interception is estimated as a product of the canopy storage capacity ( $S c$; Tables 1 and 3 ) and $A c$. The value of $S c$ can be changed to accommodate interception differences throughout the seasons (e.g. growing and dormant).

The concentration of rainwater around the tree stem (i.e. stemflow) can be quantified using field-derived coefficients $\left(a_{s}\right.$ and $b_{s}$; Tables 1 and 3 ) for a stemflow linear model (Gonzalez-Ollauri and Mickovski, 2017c). The stemflow $\left(S t ; \mathrm{mm} \mathrm{H}_{2} \mathrm{O} \mathrm{h}^{-1}\right)$ is assumed to concentrate rainfall coming from the entire tree crown $(A c)$ and to enter the soil as a jet through the soil-root zone (i.e. bypass flow; $q_{b y} ; \mathrm{mm}$ $\mathrm{H}_{2} \mathrm{O} \mathrm{h}^{-1}$; Liang et al., 2011) without accounting for the anisotropy of this zone of the soil. The stemflow is assumed to be negligible for herbaceous species.

\subsubsection{Belowground water mass balance: Infiltration and percolation}

A below ground level (b.g.l) water mass balance is performed to evaluate the effective rainfall infiltration rate $\left(q_{i} ; \mathrm{mm} \mathrm{H}_{2} \mathrm{O} \mathrm{h}^{-1}\right)$ and the subsequent percolation rate $\left(q_{p} ; \mathrm{mm} \mathrm{H}_{2} \mathrm{O} \mathrm{h}^{-1}\right)$ within the soil. The infiltration can be modelled as a piston flow (i.e. sharp wetting front) traveling through the soil at the same rate as the saturated hydraulic conductivity (Ks; Tables 1 and 3 ) after ponding has formed on the surface (i.e. wetting front saturates the soil; after Mein and Larson, 1973). All the non-infiltrating water is assumed to result in runoff $\left(R F ; \mathrm{mm} \mathrm{H}_{2} \mathrm{O} \mathrm{h}^{-1}\right)$ and exit the system. The wetting front stops moving once the rainfall ceases (i.e. $t \geq t_{r}$; Tables 1 and 4). Then, the excess water within the infiltration zone (i.e. excess water $=\theta_{s}-\theta_{f c}$; Tables 1 and 4) percolates into the underlying unsaturated soil traveling at a rate $q_{p}\left(\mathrm{~mm} \mathrm{H}_{2} \mathrm{O} \mathrm{h}^{-1}\right)$ and to a distance $z_{\text {perc }}(\mathrm{m})$ that depends on the hydraulic 
conductivity function $\left(K\left(\theta_{f}\right)\right.$; Brooks and Corey, 1964) and the final soil moisture content $\left(\theta_{f}\right)$ after percolation.

\subsubsection{Plant transpiration}

The plant transpiration rates (Etp; $\mathrm{mm} \mathrm{H}_{2} \mathrm{O} \mathrm{d}^{-1} \mathrm{~m}^{-2}$; Gonzalez-Ollauri and Mickovski, 2017c) are estimated on the basis of the potential daily evapotranspiration rate $\left(E u ; \mathrm{mm} \mathrm{H}_{2} \mathrm{O} \mathrm{d}^{-1} \mathrm{~m}^{-2}\right.$; e.g. Priestly and Taylor, 1972; Tables 1 and 4) and the vegetation cover features (i.e. crown area (Ac) for woody and leaf area index ( $L A I)$ for all plant covers; Savabi and Williams, 1995) to account for the potential direct soil evaporation rate below the plant cover $\left(E s p ; \mathrm{mm} \mathrm{H}_{2} \mathrm{O} \mathrm{d}^{-1} \mathrm{~m}^{-2}\right.$ ). When a pixel is classified as vegetated (e.g. herbs and grasses), it is assumed that the whole pixel area contributes to $E u$. Based on field observations (Gonzalez-Ollauri and Mickovski, 2017c), it is assumed that the entire root system contributes to plant transpiration. Thus, steady transpiration rates are assumed within the soil-root zone.

\subsubsection{Soil stress-state and slope stability}

Changes in the soil stress-state are evaluated through the estimation of suction stress profiles $\left(\sigma^{s}(z)\right.$; Lu et al., 2010). These can be derived from the soil matric suction profiles $\left(\left[u_{a}-u_{w}\right](z) ; \mathrm{kPa}\right)$ produced by the water fluxes within the soil under wetting (i.e. ER: effective rainfall infiltration; St: stemflow; Lu and Griffiths, 2006) and drying (i.e. plant transpiration; Etp; e.g. Gonzalez-Ollauri and Mickovski, 2017c) conditions, respectively. Suction stress can then be employed to estimate profiles of soil shear resistance $(\tau(z) ; \mathrm{kPa})$ under variable soil saturation conditions (i.e. unified effective stress principle; Lu and Likos, 2004). Subsequently, slope stability can be assessed through the calculation of a factor of safety $(F o S(z))$ with an infinite slope limit equilibrium method (i.e. $F o S=$ resisting forces/driving forces; $F o S \leq 1$ = slope failure; Craig, 2004; Lu and Godt, 2008), where the plant-soil mechanical reinforcement $\left(c_{R} ; \mathrm{kPa}\right)$ and plant surcharge $\left(W_{v} ; \mathrm{N} \mathrm{m}^{-2}\right)$ are also included.

Herein, it is assumed that slope instability events mitigated by vegetation are shallow, provided that plant-soil reinforcement tends to be limited to the topmost soil (Gonzalez-Ollauri and Mickovski, 2016; Tardio et al., 2016). Consequently, root systems tend to present a much smaller depth than the slope length at a given pixel (i.e. pixel size; $2 \times 2 \mathrm{~m}$ ), justifying the use of the infinite slope model (Craig, 2004; Lu and Godt, 2013). However, it must be borne in mind that the extent of the root system may vary on the basis of the soil and climate features (Preti et al., 2010; Gonzalez-Ollauri and

310 Mickovski, 2016). Hence, the slope stability model should be revised for the case of deep (i.e. > $1 \mathrm{~m}$ ) 311 root systems. 

fixed SSVs RF models can be fitted following the principles of the scorpan approach (McBratney et al., 2003). scorpan is a mnemonic for factors predicting soil attributes: soil, climate, organisms, relief, parent materials, age, and spatial position (Malone, 2013). Hence, a given RF model is fitted between the inputs for a given SSV and the principal terrain attributes derived from the DSM (i.e. slope, curvature, aspect), as well as the land cover found at the same locations where the SSVs are studied. SSVs are then spatially interpolated, or predicted, on the terrain attributes present over the rest of the study space. The RF models are fitted in a cascade fashion (Table 2) - i.e. each predicted SSV acts as predictor for the subsequent SSV.

All RF models are validated with a random holdback method (i.e. jackknife; Efron, 1979). Thus, each RF model is fitted with $70 \%$ of the inputs for a SSV and the other $30 \%$ (out-of-bag samples) are left for evaluating the model goodness of fit. The goodness of fit is assessed through the estimation of the coefficient of determination $\left(\mathrm{R}^{2}\right)$, the residual mean square error (RMSE) and percentage of variance explained (Malone, 2013). To ensure a reliable spatial prediction for a given SSV, the variables' sample size has to vary depending on the study site scale. It is advisable, however, to feed this module with variables sampled with an adequate spatial coverage over the study site (Malone, 2013). In our case, we employed a well-distributed sample size presenting more than 30 replicates to fit the RF models. The outcome from fitting RF for the different SSV after Plant-Best parameterisation (Section 2.7) is shown in Appendix C.

Table 2. Soil spatial variables prediction formulas and predictor variables used with the RF algorithm. Sn: sand content (\%); Sl: silt content (\%); Cl: clay content (\%); SOM: soil organic matter (\%); $\Phi$ : soil porosity (unitless).

\begin{tabular}{|l|l|}
\hline SSV & Formula and predictor variables \\
\hline Sn & Sn=slope+aspect+curvature+land cover \\
\hline Sl & Sl=slope+aspect+curvature+land cover+sand \\
\hline Cl & Cl= slope+aspect+curvature+land cover+sand+silt \\
\hline SOM & SOM= slope+aspect+curvature+land cover+sand+silt+clay \\
\hline$\Phi$ & $\Phi=$ slope+aspect+curvature+land cover+sand+silt+clay+soil organic matter \\
\hline
\end{tabular}

2.5 Module IV: Stochastic variables generator

Plant-Best implements the Monte Carlo method (MC; e.g. Ross, 2006) for the generation of stochastic model input variables from the inputs fed into Module IV (i.e. stochastic inputs, S; Table 1).

$344 \mathrm{MC}$ is employed to control the existing random environmental variability at the plant, soil, and climate compartments. Firstly, an empirical statistical distribution can be fitted to each input stochastic variable (Tables 1, 3 and 4) by using the functions provided in the R v.3.2.1 package 'fitdistrplus' (Delignette-Muller and Dutang, 2014). Then, random variable numbers are generated in the light of the fitted statistical distributions. Finally, variable values can be randomly extracted with a bootstrap method with replacement (Efron, 1979) to proceed with the subsequent model runs (Fig. 1). To ensure 
at least 30 replicates (e.g. Kar and Ramalingan, 2013). The outcome generated by Module IV after Plant-Best parameterisation (Section 2.7) is shown in Tables 3 and 4.

Plant-Best implements a series of statistical tools to manage the model uncertainty and identify the most suitable plant species against shallow landslides. It also performs a sensitivity analysis (SA) to find relevant plant traits for slope protection.

Firstly, all FoSs derived from all the model runs are pooled together per plant species and per hydrological event (i.e. wetting and drying). Then, the cumulative distribution (CDF) and probability density functions (PDF) are plotted for each treatment. Next, a Kolmogorov-Smirnov test (K-S; Hazewinkel, 2001) is carried out to compare the CDFs statistically and, as a preliminary step for plant species selection. Subsequently, an uncertainty filter is applied to each evaluated soil depth layer through the estimation of a reliability index (Malkawi et al., 2000): the bootstrapped standard deviation of the FoS values space for a given soil depth, and 1.0 is the critical FoS value. Negative RI values (i.e. RI $<0$ ) indicate reduced slope stability conditions. The statistical differences between the RIs under vegetated and fallow soil covers, and under wetting and drying conditions, are evaluated with Kruskal-Wallis (i.e. between groups differences) and Wilcoxon (i.e. within groups differences) tests at the $95 \%$ and $99 \%$ confidence levels. The most suitable plant species can be finally selected in the light of the obtained RI outcomes.

Eventually, to highlight the most relevant traits for plant selection, the sensitivity of the model stochastic input variables (Table 1) is studied with the One-At-A-Time approach (Daniel, 1973). This assess the effect of each stochastic variable on the factor of safety (FoS) after changing each variable mean value by $+20 \%$ and $-20 \%$, respectively, and evaluating the resulting percentages of variation (PV; Félix and Xanthoulis, 2005).

\subsection{Plant-Best parameterisation}

\subsubsection{Study site}

Plant-Best was employed on a site with a history of slope failures located adjacent to

385 Catterline Bay, Aberdeenshire, UK (WGS84 Long: -2.21 Lat: 56.90; Fig. 4), with a mean annual temperature of $8.9^{\circ} \mathrm{C}$ and a mean annual rainfall of $565.13 \mathrm{~mm}$ (Gonzalez-Ollauri and Mickovski, 2016). The site topography is dominated by sloped $\left(25-50^{\circ}\right)$ terrain and cliffs dropping into the North Sea (Fig. 4). These are combined with a flatter inland area that is crossed by a stream leading to the formation of inclined riverbanks (Fig. 4). Generally, shallow (ca. 0.6-1.0 m deep) silty sand soils can be found resting on conglomerate bedrock. The vegetation of the study site is characteristic of 
temperate humid climates, comprising herbaceous weeds and grasses associated to disturbed grounds (Gonzalez-Ollauri and Mickovski, 2017b) intermixed with areas dominated by riparian trees and shrubs (e.g. willow, sycamore, ash, hawthorn), where oak and beech individuals can be also found.

394 Agricultural crops of wheat, barley and potatoes surround the study site.

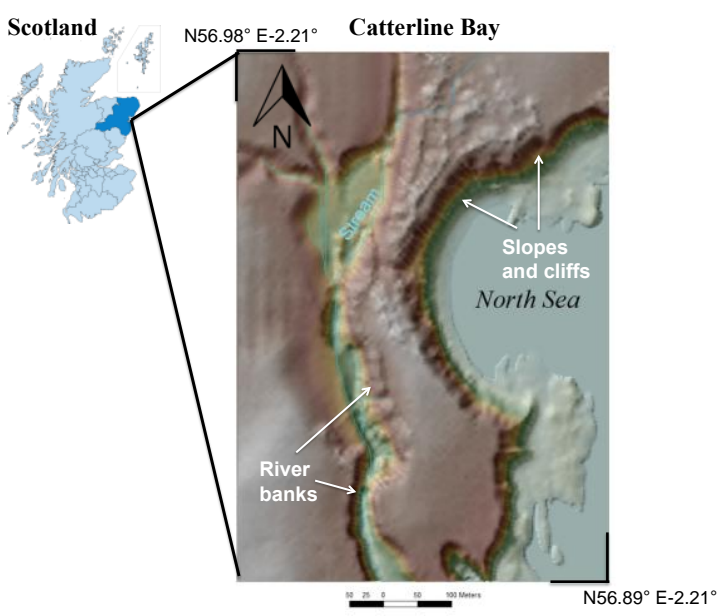

Figure 4. Study site location and topography.

\subsubsection{Plant inputs}

Five native plant species were chosen for implementing Plant-Best: three woody - i.e. sycamore (Acer pseudoplatanus L.), ash (Fraxinus excelsior L.) and willow (Salix sp.); and two herbaceous species - i.e. red campion (Silene dioica Clariv.) and blue fleabane (Erigeron acris L.). To obtain the necessary plant inputs for operating Plant-Best (see Table 1), ten adult (i.e. > 10 years for woody species; apex of the growing season for herbaceous species) individuals of each plant species were selected for parameterisation. For illustrative purposes, two extra woody species were evaluated i.e. beech (Fagus sylvatica L.) and composite oak (Quercus sp.), for which the required inputs were retrieved from the literature and online databases (e.g. DAAC, DRYAD, Bischetti et al., 2005, Burylo et al., 2011).

Well-established methods were employed to measure all the required plant inputs (Table 1) for the selected woody individuals. The leaf area index ( $L A I)$ was quantified with the direct method (Wolf et al., 1972; Breda, 2003). The diameter at breast height (DBH) was measured according to the existing specifications (Powel, 2005). The canopy-crown area (Ac) was estimated according to the Spoke's distance method (Blozan, 2006). Four individuals per species were selected to quantify the canopy rainfall storage capacity $(S c)$ and the stemflow coefficients ( $a_{s}$ and $b_{s}$ ). The former was appraised by collecting and comparing the gross versus the intercepted rainfall below the tree canopy over time (Gonzalez-Ollauri and Mickovski, 2017c). Stemflow coefficients were estimated by examining the linear relationship between the concentration of rainfall around the individual stems and the gross rainfall for different precipitation events (Gonzalez-Ollauri and Mickovski, 2017c). The mean root tensile strength $(T r ; \mathrm{kPa})$ was measured for each species with a universal tensile testing machine (Mickovski et al., 2009) using fine root (i.e. diameter $<3.5 \mathrm{~mm}$ ) samples collected during the 
vegetative season. Root size selection was done in agreement with SPM limitations -i.e. only small roots break upon slope failure (Stokes et al., 2008).

For the herbaceous species, $L A I, S c$, and $T r$ were quantified with the same methods indicated above. The aboveground biomass per unit area $(M a)$ was measured by harvesting and oven-drying $\left(70^{\circ}, 48 \mathrm{~h}\right)$ all the plant material falling within a $0.5 \mathrm{~m}^{2}$ aluminium quadrat at 59 different sampling locations spread over the study site (Gonzalez-Ollauri and Mickovski, 2017b). The allometric relationship between above and belowground plant biomass ( $\alpha_{a}$ and $\beta_{a}$; Cheng and Niklas, 2007) was measured for 20 herbaceous individuals (i.e. 10 per species) by assessing the mathematical relationship between the dry biomass of both vegetative parts (i.e. shoot + leaves vs. root: Gonzalez-Ollauri and Mickovski, 2016). The allometric relationship for all the woody species, however, was retrieved from Cheng and Niklas (2007) for broadleaf temperate species. Eventually, for the two extra evaluated woody species - i.e. beech and oak, the required inputs were retrieved from the literature and online databases - i.e. DBH and Ac: Evans et al., 2015 (UK data, DRYAD); LAI: Scurlock et al., 2001 (Temperate Europe data, DAAC); $S c, a_{s}$ and $b_{s}$ : Deguchi et al., 2006 (worldwide broadleaf deciduous forests); $T r$ : Bischetti et al. 2005 and Burylo et al., 2011 (Temperate Europe data). The light extinction coefficient $\left(k_{c}\right)$ was assumed to be the same for all plant species, and its range of values was obtained from Deguchi et al. (2006). The root mass density $\left(\rho_{\mathrm{r}}\right)$, which could have been measured with the volume displacement method (Hughes, 2005), was assumed to vary randomly between 0.4 and $0.9 \mathrm{~g}$ $\mathrm{cm}^{-3}$ for all species, as plant roots are expected to float in water (i.e. roots are less dense than water).

The outcome from the parameterisation of the required plant inputs (Table 1) is shown in Table 3.

For the parameterisation of the fixed SSVs (Tables 1 and 4), 43 undisturbed soil core samples from the uppermost $400 \mathrm{~mm}$ b.g.l. were collected at random locations distributed over the study site (Fig. 4). For this, an aluminium core sampler of $95 \mathrm{~mm}$ (inner diameter) and $150 \mathrm{~mm}$ (height) was used. Standard methods were employed for determining the soil particle size distribution (PSD: percentage of sand $(\mathrm{Sn})$, percentage of silt $(\mathrm{St})$ and percentage of clay $(\mathrm{Cl})$; BS 1377-2:1990), porosity ( $\Phi$; Head, 1980) and organic matter content (SOM; Schulte and Hopkins, 1996) at each sampling location. The soil hydrological properties soil moisture at field capacity $\left(\theta_{f_{c}}\right)$, soil moisture at wilting

$453 \mathrm{~s}^{-1}$ ) were predicted by means of pedotransfer functions (Saxton and Rawls, 2006; Toth et al., 2015) 454 using the measured SSVs as input.

With regard to the soil stochastic variables (Table 1), the soil mechanical parameters $c$ ' 456 (effective cohesion) and $\phi^{\prime}$ (angle of internal friction) were obtained by means of direct shear tests (BS 457 1377-7, 1990; Head and Epps, 2011) carried out on the soil core samples collected from the study site.

458 The soil hydro-mechanical parameters $\alpha$ (inverse of the air entry pressure) and $n$ (pore size distribution parameter) were retrieved from soil water characteristic curves (SWCC; van Genuchten, 1980) fitted 

in the laboratory (remoulded soil conditions; Schindler and Muller, 2006).

$$
\text { 2.7.4 Climate inputs }
$$

Long-term (1996-2014) daily cumulative rainfall information $\left(P g ; \mathrm{mm} \mathrm{H}_{2} \mathrm{O} \mathrm{d}^{-1}\right)$ and climatic inputs for the estimation of the potential evapotranspiration $\left(E u ; \mathrm{mm} \mathrm{H}_{2} \mathrm{O} \mathrm{d}^{-1} \mathrm{~m}^{-2}\right.$; Priestly and Taylor, 1972 ) - i.e. daily air temperature, atmospheric pressure and sunshine duration, were retrieved from the MIDAS dataset (UK Met Office, 2015; Station: Netherley, UK). The mean rainfall intensity per event and frequency of rainfall events during the growing season $\left(\alpha_{c}\right.$ and $\lambda_{c}$; Preti et al., 2010) were also retrieved from the abovementioned meteorological records. $\alpha_{c}$ and $\lambda_{c}$ determine, along with a number of soil features (i.e. water available to plants), the rooting depth of the vegetation for temperate humid climates (Gonzalez-Ollauri and Mickovski, 2016) and for dry climates (Preti et al., 2010).

The outcome from the parameterisation of the required climate inputs (Table 1) is shown in Table 4.

\subsection{Plant-Best runs and assumptions}

To test Plant-Best, 50 model runs evaluated on 4837 landslide-prone pixels and at 10 different soil depths (i.e. every $0.1 \mathrm{~m}$ between ground surface and $1.0 \mathrm{~m}$ b.g.l., assuming $1.0 \mathrm{~m}$ deep isotropic soil columns) were carried out per plant species and under fallow soil conditions. The fixed SSV were generated from the selection of the best RF model fit out of 100 possible fits (Appendix C). All the stochastic model inputs (Tables 1, 3, and 4) were varied one-at-a-time over the study site space per model run. However, the soil hydro-mechanical parameters $\left(\phi^{\prime}, \alpha\right.$, and $n$; Table 1) were allowed to vary randomly, within the limits established by their statistical distribution (Table 4), over the study site space in every model run.

To stress the positive or negative effects of vegetation in a landslides context, the height of the ground water table $\left(H_{w t}\right)$ was fixed at the lower boundary of the system (i.e. $1.0 \mathrm{~m}$ ) and was not allowed to vary between runs (i.e. perched water table neglected based on encountered soil type and observation). The soil cohesion ( $\left.c^{\prime}\right)$ was set to $0 \mathrm{kPa}$ for all the model runs in order to highlight the effects provided by the root apparent cohesion $\left(c_{R}\right)$. The stemflow coefficients $\left(a_{s}\right.$ and $b_{s}$; Table 1$)$ were obtained from the pool of studied individuals, and the same statistical distribution assigned to every woody species (Table 3). With this, we intended to highlight the effects from other plant traits (e.g. $D B H, A c$; Table 3). Under vegetated cover, the soil pore-size distribution parameter $\left(n_{v}\right)$ was forced to be below or equal to 2 (Carminati et al., 2010), provided that the suction stress function $\left(\sigma^{s}\right.$; see

496 Appendix A), featured within the unified effective stress principle ( $\mathrm{Lu}$ and Likos, 2004), presents a minimum at greater values of $n$ (Lu et al., 2010). 
Table 3. Plant inputs required for operating Plant-Best obtained from the parameterisation process and implementation of Module IV for the stochastic variables. LAI: leaf area index; Ac: canopy-crown area $\left(\mathrm{m}^{2}\right)$; DBH: diameter at breast height $(\mathrm{cm}) ; \alpha_{\mathrm{a}}:$ allometric power-law parameter; $\beta_{\mathrm{a}}:$ allometric scaling parameter; $\rho_{\mathrm{r}}$ : root mass density $\left(\mathrm{g} \mathrm{cm}^{-3}\right) ; \mathrm{k}_{\mathrm{c}}:$ light extinction

501 coefficient; Sc: canopy storage capacity $\left(\mathrm{mm} \mathrm{m}^{-2}\right) ; \mathrm{a}_{\mathrm{s}}$ : stemflow regression line intercept; $\mathrm{b}_{\mathrm{s}}$ : stemflow regression line slope; Tr: root tensile strength (MPa); Ma: aboveground biomass $\left(\mathrm{g} \mathrm{m} \mathrm{m}^{-2}\right)$

502 Type: S: stochastic; F: fixed. D: statistical distribution; N: normal; LN: lognormal GM: gamma; W: weibull; U: uniform; LG: logistic; B: binomial; Subscripts: t: log-transform; tr: truncated; sc:

\begin{tabular}{|c|c|c|c|c|c|c|c|c|c|c|c|c|c|c|c|c|c|c|c|c|c|}
\hline & & \multicolumn{4}{|c|}{ Acer pseudoplatanus } & \multicolumn{4}{|c|}{ Fraxinus excelsior } & \multicolumn{4}{|c|}{ Salix sp. } & \multicolumn{4}{|c|}{ Silene dioica } & \multicolumn{4}{|c|}{ Erigeron acris } \\
\hline Input & Type & $\mathrm{D}$ & $\mathrm{a}$ & $\mathrm{b}$ & $\mathrm{m} \pm \mathrm{sd}$ & $\mathrm{D}$ & $\mathrm{a}$ & $\mathrm{b}$ & $\mathrm{m} \pm \mathrm{sd}$ & $\mathrm{D}$ & $\mathrm{a}$ & $\mathrm{b}$ & $\mathrm{m} \pm \mathrm{sd}$ & $\mathrm{D}$ & $\mathrm{a}$ & $\mathrm{b}$ & $\mathrm{m} \pm \mathrm{sd}$ & $\mathrm{D}$ & $\mathrm{a}$ & B & $\mathrm{m} \pm \mathrm{sd}$ \\
\hline$L A I$ & $\mathrm{~S}$ & $\mathrm{LN}_{\mathrm{t}}$ & 0.60 & 0.08 & $6.26 \pm 0.92$ & GM & 3.44 & 0.70 & $4.93 \pm 2.54$ & $\mathrm{U}$ & 1.01 & 5.57 & $3.34 \pm 1.31$ & $\mathrm{G}$ & 1.78 & 0.42 & $4.14 \pm 3.28$ & G & 1.78 & 0.42 & $4.14 \pm 3.28$ \\
\hline$A c$ & $\mathrm{~S}$ & $\mathrm{~N}_{\mathrm{t}}$ & 3.40 & 0.88 & $46.04 \pm 47.94$ & $\mathrm{~N}_{\mathrm{t}}$ & 3.34 & 0.84 & $42.42 \pm 42.85$ & LN & 2.33 & 0.61 & $12.35 \pm 7.66$ & & & & & & & & \\
\hline$D B H$ & $\mathrm{~S}$ & $\mathrm{LN}_{\mathrm{t}}$ & 1.08 & 0.17 & $23.74 \pm 15.71$ & $\mathrm{GM}_{\mathrm{t}}$ & 56.24 & 18.68 & $22.33 \pm 9.57$ & $\mathrm{U}$ & 10.66 & 43.93 & $27.24 \pm 9.63$ & & & & & & & & \\
\hline$\alpha_{a}$ & $\mathrm{~S}$ & $\mathrm{~N}_{\mathrm{tr}}$ & 0.82 & 0.52 & $0.82 \pm 0.52$ & $\mathrm{~N}_{\mathrm{tr}}$ & 0.82 & 0.52 & $0.82 \pm 0.52$ & $\mathrm{~N}_{\mathrm{tr}}$ & 0.82 & 0.52 & $0.82 \pm 0.52$ & $\mathrm{~N}$ & 0.81 & 0.15 & $0.81 \pm 0.15$ & $\mathrm{~N}$ & 0.81 & 0.15 & $0.81 \pm 0.15$ \\
\hline$\beta_{a}$ & $\mathrm{~S}$ & $\mathrm{~N}_{\mathrm{tr}}$ & 4.55 & 7.29 & $4.55 \pm 7.29$ & $\mathrm{~N}_{\mathrm{tr}}$ & 4.55 & 7.29 & $4.55 \pm 7.29$ & $\mathrm{~N}_{\mathrm{tr}}$ & 4.55 & 7.29 & $4.55 \pm 7.29$ & $\mathrm{~N}$ & 7.01 & 0.25 & $7.01 \pm 0.25$ & $\mathrm{~N}$ & 7.01 & 0.25 & $7.01 \pm 0.25$ \\
\hline$\rho_{r}$ & $\mathrm{~s}$ & $\mathrm{~N}$ & 0.65 & 0.125 & $0.65 \pm 0.125$ & $\mathrm{~N}$ & 0.65 & 0.125 & $0.65 \pm 0.125$ & $\mathrm{~N}$ & 0.65 & 0.125 & $0.65 \pm 0.125$ & $\mathrm{~N}$ & 0.65 & 0.125 & $0.65 \pm 0.125$ & $\mathrm{~N}$ & 0.65 & 0.125 & $0.65 \pm 0.125$ \\
\hline$S c$ & F & & & & $0.22 \pm 0.22$ & & & & $0.26 \pm 0.08$ & & & & $0.72 \pm 0.36$ & & & & $1.91 \pm 0.23$ & & & & $1.91 \pm 0.23$ \\
\hline$a_{s}$ & $\mathrm{~S}$ & $\mathrm{~B}_{\mathrm{sc}}$ & 0.32 & 0.97 & & $\mathrm{~B}_{\mathrm{sc}}$ & 0.32 & 0.97 & & $\mathrm{~B}_{\mathrm{sc}}$ & 0.32 & 0.97 & & $\mathrm{~B}_{\mathrm{sc}}$ & 0.32 & 0.97 & & $\mathrm{~B}_{\mathrm{sc}}$ & 0.32 & 0.97 & \\
\hline$b_{s}$ & $\mathrm{~S}$ & LN & -4.42 & 0.84 & & $\mathrm{LN}$ & -4.42 & 0.84 & & $\mathrm{LN}$ & -4.42 & 0.84 & & $\mathrm{LN}$ & -4.42 & 0.84 & & $\overline{\mathrm{LN}}$ & -4.42 & 0.84 & \\
\hline$T r$ & $\mathrm{~S}$ & LN & 2.96 & 0.75 & $25.65 \pm 20.47$ & LN & 2.96 & 0.75 & $25.29 \pm 20.59$ & LN & 3.01 & 0.93 & $31.00 \pm 45.35$ & LN & 3.14 & 0.67 & $29.07 \pm 25.35$ & $\mathrm{LN}$ & 3.00 & 0.71 & $25.57 \pm 20.44$ \\
\hline$M a$ & $\mathrm{~S}$ & & & & & & & & & & & & & $\mathrm{~W}_{\mathrm{t}}$ & 8.78 & 6.47 & $598.15 \pm 465.0$ & $\mathrm{~W}_{\mathrm{t}}$ & 8.78 & 6.47 & $598.15 \pm 465.0$ \\
\hline
\end{tabular}

Table 3 Continued. Plant inputs required for operating Plant-Best obtained from the parameterisation process and implementing Module IV for the stochastic variables. LAI: leaf area index; Ac: canopy-crown area $\left(\mathrm{m}^{2}\right)$; DBH: diameter at breast height $(\mathrm{cm}) ; \alpha_{\mathrm{a}}$ : allometric power-law parameter; $\beta_{\mathrm{a}}:$ allometric scaling parameter; $\rho_{\mathrm{r}}:$ root mass density $\left(\mathrm{g} \mathrm{cm}^{-3}\right) ; \mathrm{k}_{\mathrm{c}}:$ light extinction coefficient; Sc: canopy storage capacity $\left(\mathrm{mm} \mathrm{m}^{-2}\right)$; $\mathrm{a}_{\mathrm{s}}$ : stemflow regression line intercept; $\mathrm{b}_{\mathrm{s}:}$ stemflow regression line slope; Tr: root tensile strength (MPa); Ma: aboveground biomass $\left(\mathrm{g} \mathrm{m}^{-2}\right)$

507 Type: S: stochastic; F: fixed. D: statistical distribution; N: normal; LN: lognormal GM: gamma; W: weibull; U: uniform; LG: $\operatorname{logistic;}$ B: binomial; Subscripts: t: log-transform; tr: truncated; sc:

508 scaled between 0 and 1 . a and b: statistical distribution fit coefficients; $m \pm$ sd: mean \pm standard deviation.

\begin{tabular}{|c|c|c|c|c|c|c|c|c|c|}
\hline & & \multicolumn{4}{|c|}{ Fagus sylvatica } & \multicolumn{4}{|c|}{ Quercus sp. } \\
\hline Input & Type & $\mathrm{D}$ & $\mathrm{a}$ & $\mathrm{b}$ & $\mathrm{m} \pm \mathrm{sd}$ & $\mathrm{D}$ & $\mathrm{a}$ & $\mathrm{b}$ & $\mathrm{m} \pm \mathrm{sd}$ \\
\hline LAI & $\mathrm{S}$ & $\mathrm{W}$ & 4.16 & 5.08 & $4.70 \pm 1.27$ & $\mathrm{~W}$ & 4.30 & $6.69^{\dagger}$ & $6.45 \pm 1.61$ \\
\hline$A c$ & $\mathrm{~S}$ & $\mathrm{LG}_{\mathrm{t}}$ & 3.83 & 0.50 & $66.99 \pm 80.00$ & $\mathrm{~N}_{\mathrm{t}}$ & 3.32 & 1.11 & $48.72 \pm 68.78$ \\
\hline$D B H$ & $\mathrm{~S}$ & $\mathrm{LN}_{\mathrm{t}}$ & 1.20 & 0.17 & $34.65 \pm 24.37$ & $\overline{\mathrm{LN}_{\mathrm{t}}}$ & 1.17 & 0.18 & $31.61 \pm 26.07$ \\
\hline$\alpha_{a}$ & $\mathrm{~S}$ & $\mathrm{~N}_{\mathrm{tr}}$ & 0.82 & 0.52 & $0.82 \pm 0.52$ & $\mathrm{~N}_{\mathrm{tr}}$ & 0.82 & 0.52 & $0.82 \pm 0.52$ \\
\hline$\beta_{a}$ & $\mathrm{~S}$ & $\mathrm{~N}_{\mathrm{tr}}$ & 4.55 & 7.29 & $4.55 \pm 7.29$ & $\mathrm{~N}_{\mathrm{tr}}$ & 4.55 & 7.29 & $4.55 \pm 7.29$ \\
\hline$\rho_{r}$ & $\mathrm{~N}$ & $\mathrm{~N}$ & 0.65 & 0.125 & $0.65 \pm 0.125$ & $\mathrm{~N}$ & 0.65 & 0.125 & $0.65 \pm 0.125$ \\
\hline$k_{c}$ & $\mathrm{~S}$ & $\mathrm{~N}$ & 0.6 & 0.15 & $0.60 \pm 0.15$ & $\mathrm{~N}$ & 0.6 & 0.15 & $0.60 \pm 0.15$ \\
\hline$S c$ & $\mathrm{~S}$ & $\mathrm{~N}$ & 0.96 & 0.35 & $0.96 \pm 0.35$ & $\mathrm{~N}$ & 0.96 & 0.35 & $0.96 \pm 0.35$ \\
\hline$a_{s}$ & $\mathrm{~S}$ & $\mathrm{~B}_{\mathrm{sc}}$ & 0.32 & 0.97 & & $\mathrm{~B}_{\mathrm{sc}}$ & 0.32 & 0.97 & \\
\hline$b_{s}$ & $\mathrm{~S}$ & LN & -4.42 & 0.84 & & LN & -4.42 & 0.84 & \\
\hline$T r$ & $\mathrm{~S}$ & $\mathrm{LN}_{\mathrm{t}}$ & 1.17 & 0.01 & $25.07 \pm 0.78$ & $\mathrm{LN}_{\mathrm{t}}$ & 0.92 & 0.15 & $13.70 \pm 6.20$ \\
\hline
\end{tabular}


Table 4. Soil and climate inputs required for operating Plant-Best obtained from the parameterisation process and implementation of Module IV for the stochastic variables. $\theta_{\mathrm{i}}$ : initial soil moisture; $\alpha$ : inverse air-entry pressure $\left(\mathrm{kPa}^{-1}\right) ; \mathrm{n}$ : pore-size distribution parameter; $\alpha_{\mathrm{v}}$ : inverse air-entry pressure vegetated soil $\left(\mathrm{kPa}^{-1}\right) ; \mathrm{n}_{\mathrm{v}}$ : pore-size distribution parameter vegetated soil; c': effective cohesion $(\mathrm{kPa}) ; \phi '$ : angle of internal friction $\left({ }^{\circ}\right)$; $\mathrm{Sn}$ : sand content (\%); Cl: clay content (\%); SOM: soil organic matter (\%; $\Phi$ : soil porosity; $\theta_{\mathrm{s}}$ : soil moisture at saturation; $\theta_{\mathrm{fc}}$ : soil moisture at field capacity; $\theta_{\mathrm{wp}}$ : soil moisture at wilting point; Ks: saturated hydraulic conductivity $\left(\mathrm{m} \mathrm{s}^{-1}\right)$; $\varphi_{\mathrm{w}}$ : wetting front hydraulic head (m); Gs: specific gravity; $\gamma_{\mathrm{w}}$ : unit weight of water $\left(\mathrm{kPa} \mathrm{m}^{-1}\right) ; \mathrm{H}_{\mathrm{w}}$ : groundwater table height (m); Pg: gross rainfall $(\mathrm{mm})$; tr: rainfall duration $(\mathrm{h}) ; \alpha_{\mathrm{c}}$ : mean rainfall intensity per event (mm event ${ }^{-}$ $\left.{ }^{1}\right) ; \lambda_{\mathrm{c}}$ : frequency of rainfall events; Eu: potential daily evapotranspiration rate $\left(\mathrm{mm} \mathrm{d}^{-1} \mathrm{~m}^{-2}\right)$. Type: $\mathrm{S}$ : stochastic variable; Fm: fixed variable. D: statistical distribution; N: normal; LN: lognormnal; U: uniform; B: beta; Subscripts: t: log-transformed; sc: scaled between 0 and 1. a and b: statistical distribution fit coefficients; $\mathrm{m} \pm \mathrm{sd}$ : mean variable value \pm standard deviation

\begin{tabular}{|c|c|c|c|c|c|c|}
\hline Compartment & Input & Type & $\mathrm{D}$ & $\mathrm{a}$ & $\mathrm{b}$ & $\mathrm{m} \pm \mathrm{sd}$ \\
\hline \multirow[t]{19}{*}{ Soil } & $\theta i$ & $\mathrm{~S}$ & $\mathrm{U}$ & 0.09 & 0.7 & \\
\hline & $\alpha$ & $\mathrm{S}$ & $\bar{U}$ & 0.05 & 0.29 & $0.17 \pm 0.07$ \\
\hline & $n$ & $\mathrm{~S}$ & $\mathrm{U}$ & 1.8 & 6 & $3.93 \pm 1.24$ \\
\hline & $\alpha v$ & $\mathrm{~S}$ & $\mathrm{U}$ & 0.0065 & 0.05 & $0.03 \pm 0.01$ \\
\hline & $n v$ & $\mathrm{~S}$ & $\bar{U}$ & 1 & 2 & $1.51 \pm 0.29$ \\
\hline & $c^{\prime}$ & $\mathrm{S}$ & LN & 3.33 & 0.57 & $33.44 \pm 22.71$ \\
\hline & $\phi^{\prime}$ & $\mathrm{S}$ & LN & 2.98 & 0.51 & $22.09 \pm 11.55$ \\
\hline & $S n$ & $\mathrm{~F}$ & & & & $74.97 \pm 2.47$ \\
\hline & $\mathrm{Cl}$ & $\mathrm{F}$ & & & & $1.60 \pm 0.12$ \\
\hline & SOM & $\mathrm{F}$ & & & & $5.57 \pm 0.65$ \\
\hline & $\Phi$ & $\mathrm{F}$ & & & & $0.68 \pm 0.02$ \\
\hline & $\theta s$ & $\mathrm{~F}$ & & & & $0.60 \pm 0.02$ \\
\hline & $\theta f c$ & $\mathrm{~F}$ & & & & $0.23 \pm 0.003$ \\
\hline & $\theta w p$ & F & & & & $0.09 \pm 0.001$ \\
\hline & $K s$ & $\mathrm{~F}$ & & & & $5.82 \mathrm{e}-5 \pm 1.43 \mathrm{e}-5$ \\
\hline & $\varphi_{w f}$ & $\mathrm{~F}$ & & & & $0.006 \pm 0.006$ \\
\hline & Gs & $\mathrm{F}$ & & & & 2.87 \\
\hline & $\gamma_{w}$ & $\mathrm{~F}$ & & & & 9.8 \\
\hline & $H_{w t}$ & F & & & & 1.00 \\
\hline \multirow[t]{5}{*}{ Climate } & $P g$ & $\mathrm{~S}$ & LN & 0.46 & 1.54 & $4.94 \pm 11.81$ \\
\hline & $t r$ & $\mathrm{~F}$ & & & & 24 \\
\hline & $\alpha_{c}$ & $\mathrm{~S}$ & $\mathrm{~N}_{\mathrm{t}}$ & 1.68 & 0.47 & $5.92 \pm 2.96$ \\
\hline & $\lambda_{c}$ & $\mathrm{~S}$ & $\mathrm{~N}$ & 0.62 & 0.10 & $0.64 \pm 0.02$ \\
\hline & $E u$ & $\mathrm{~S}$ & $\mathrm{~B}_{\mathrm{sc}}$ & 0.77 & 1.86 & $1.01 \pm 1.01$ \\
\hline
\end{tabular}

Eventually, the connectivity between the site grid pixels was suppressed (i.e. no lateral flow and no runoff infiltration occurs between adjacent pixels) as little runoff is expected to infiltrate into soil columns where ponding is taking place (Mein and Larson, 1973), and as the evaluated time step (i.e. $24 \mathrm{~h}$; event-based; Table 4) was short enough to prevent the arrival of the wetting front to the system lower boundary and produce lateral flow (Neitsch et al., 2011). With this assumption the computational effort was reduced. 
Plant-Best successfully identified slope failure prone zones within the study site (Fig. 5a,b). These zones were detected on the basis of the proximity to water accumulation areas (Fig. 5a), which are most prone to instability. Most of the landslides detected (Fig. 5c) corresponded to shallow slope movements on steep terrain, where mainly herbs and grasses comprised the vegetation cover (Gonzalez-Ollauri and Mickovski, 2017b). However, deeper landslides were also detected (e.g. D in Fig.5c). The use of topographic attributes (e.g. slope, curvature, aspect) implicit within the framework (Fig. 2) was proven to be effective for identifying zones subject to slope failure (e.g. Gorokhovich et al., 2015; Vorpahl et al., 2012), with the added value that the DSM was the only input required (Fig. 2).

The total predicted area subject to slope instability was of $19348 \mathrm{~m}^{2}$, and the shallow landslide susceptibility $(\mathrm{P}(\%)=100 x($ landslide area/total area); Cimini et al., 2015) was of $6.72 \%$. Thus, PlantBest's simplified approach was shown to be useful for the preliminary evaluation of the degree of intervention needed against landslides, or for the identification of priority zones for action. Albeit landslide susceptibility may seem small for our study area, this should be incorporated within risk assessment approaches to determine the potential impact produced by landslides (e.g. Mickovski, 2014). The spatial nature of the outcome from Plant-Best's Module I (Section 2.2) makes it ready to be employed within landslide risk mapping and assessments (van Westen et al., 2006). Nonetheless, we recommend carrying out ground validation (e.g. Fig 5c) upon employing Plant-Best for the detection of landslide-prone zones, as knowledge of the soil physical properties (e.g. c', ф', PSD, Ks, thickness, etc.) is crucial for evaluating slope failure hazards (e.g. Lu and Godt, 2013; Schiliro et al., 2016).

3.2. Plant-species suitability for slope protection

3.2.1. Cumulative distribution functions (CDFs), probability density functions (PDFs) and Kolmogorov-Smirnov (K-S) tests

Plant-Best predicted clear differences between vegetated and fallow soil covers under both

$5636 \mathrm{a}, \mathrm{d})$ showed that the slope failure likelihood (i.e. $\mathrm{FoS}<1$ ) was lower for the vegetated than for the

564 fallow cover in all cases. In particular, this effect was stronger under drying conditions (Fig. 6d), when

565 the effects of both soil-root mechanical reinforcement and plant transpiration are taking place together.

566 Differences between fallow and vegetated soil covers were more evidently seen in the probability

567 density functions (PDFs: Figs. 6b,e). Vegetation PDFs tended to become flatter with respect to the

568 fallow soil for the higher values of the FoS. This indicates that the slope stability conditions improved

569 under the vegetation cover, as vegetation provided mechanical and hydrological reinforcement to the soil (Stokes et al., 2008; Gonzalez-Ollauri and Mickovski, 2017a, 2017c). 
(a) Water accumulation zones

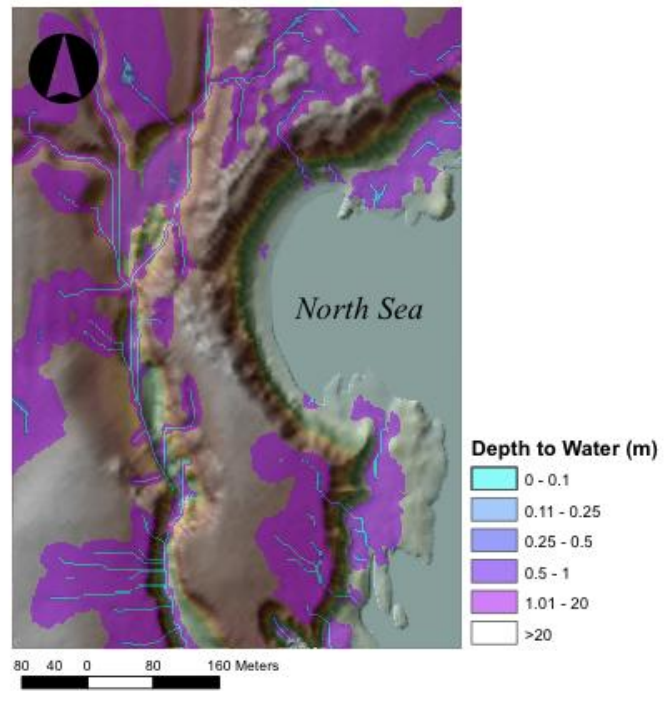

(b)

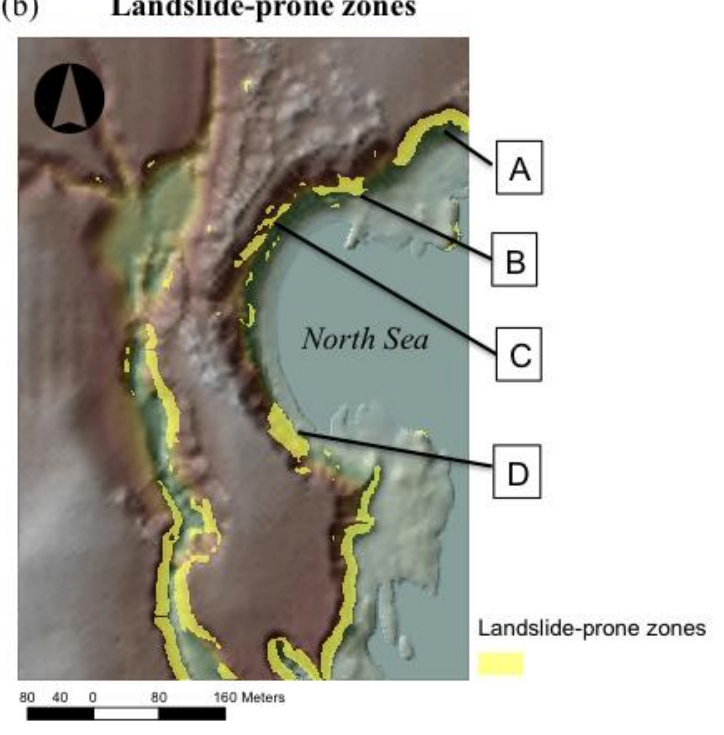

(c)

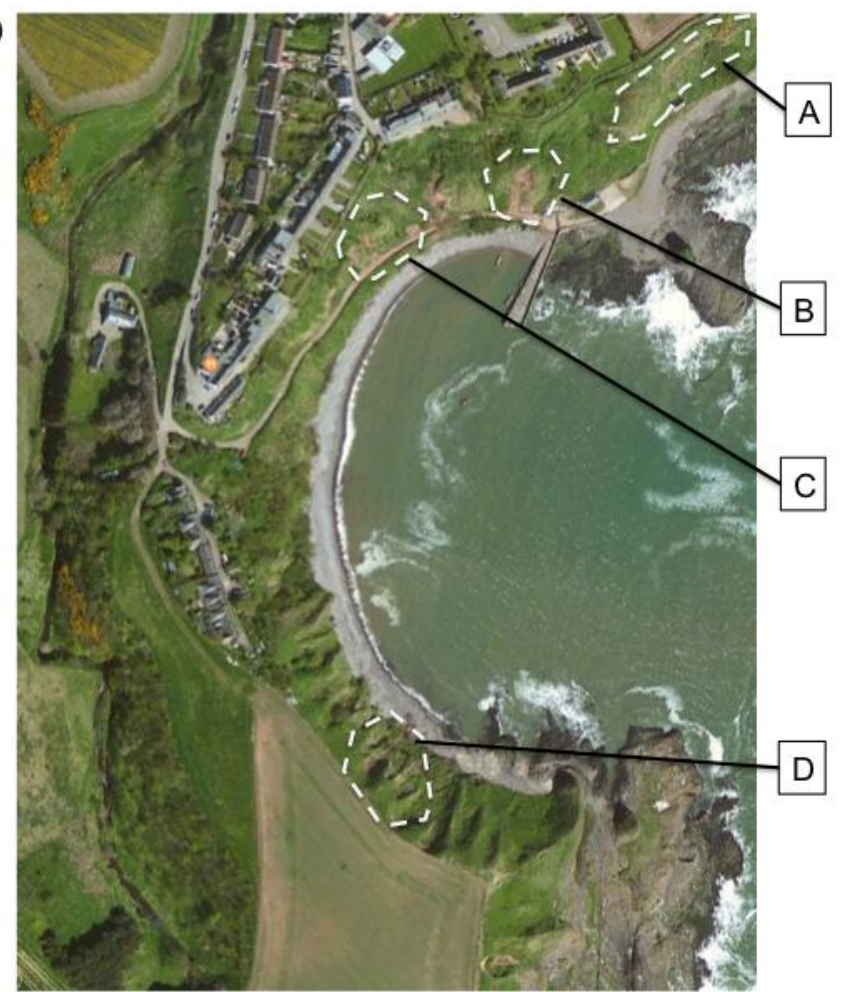

Figure 5. (a) Zones of water accumulation defined on the basis of the cartographic Depth-to-Water $\left(\mathrm{D}_{\mathrm{TW}}\right)$ index. (b) Zones prone of slope failure. (c) Ground validation of selected landslide zones. Aerial image: GetMapping (2014). 
The outcomes from the CDFs and PDFs (Figs. 6a-b,c-d) indicated that the FoS presented a statistical lognormal distribution (Haneberg, 2004; Frattini et al., 2009; Arnone et al., 2014) for both vegetated and fallow soil covers (Table 5). These outcomes stand for statistical or probabilistic models on their own (Table 5; Haneberg, 2004; Vorpahl et al., 2012) that can be readily applied for predicting plant-derived slope protection within our study site (e.g. Figs. 8a-h). In addition, the information given in the CDFs and PDFs could be directly used to make decisions upon which plant species may lead to a better slope protection performance. However, we believe that the CDFs and PDFs outcomes were not informative enough to identify the most suitable plant species (i.e. PDF range was quite narrow: 0.30.4 around $\mathrm{FoS}=1$ ) and, hence, we undertook further illustrative steps.
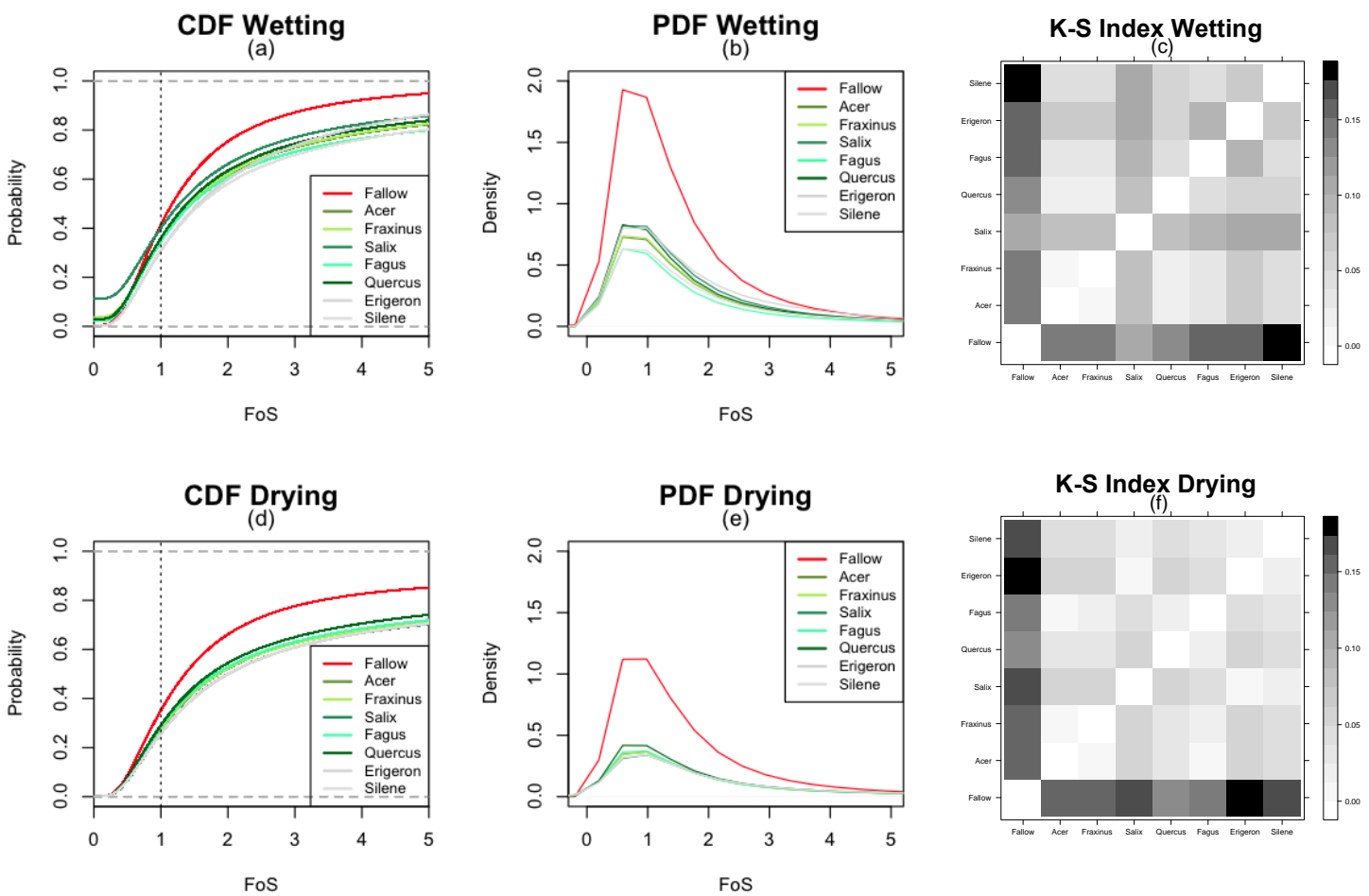

581 Figure 6. a-c) Cumulative distribution functions (CDFs), probability density functions (PDFs) and KolmogorovSmirnov (K-S) test outcomes generated by Plant-Best for the different tested plant covers and under wetting ( Smirnov (K-S) test outcomes generated by Plant-Best for the different tested plant covers and under drying conditions. K-S charts show the K-S index (D) values coming from the CDFs comparison between the considered

The differences between plant species observed in the CDFs and PDFs (Figs. 6a-b,c-d) became clearer after performing pairwise K-S tests between the obtained CDFs (Figs. 6c,f). The two species of herbs tested (i.e. Silene dioica and Erigeron acris) stand out with respect to the woody species and the fallow soil under wetting and drying conditions, respectively. Silene dioica differed the most from the woody and fallow covers under wetting conditions $(\mathrm{D}=0.18, \mathrm{p}<0.01)$, while Erigeron acris presented the greatest differences with respect to the other considered cases under drying circumstances $(\mathrm{D}=0.17, \mathrm{p}<0.01)$. This may suggest that herbaceous plants have a better slope protection performance than woody species. Nonetheless, on the basis of the K-S outcomes alone (Fig. $6 c, f)$ it cannot be concluded whether the observed differences were positive or negative for slope 
protection. Besides, K-S outcomes still carried the uncertainty provided by the randomness of the Plant-Best inputs (Tables 3 and 4). For this, the estimation of Reliability Indices (RIs; Malkawi et al., 2000) became decisive to further illustrate the previous outcomes, and support an eventual plant selection. The same applies to the studied woody species, where Fagus sylvatica $(\mathrm{D}=0.16, \mathrm{p}<0.01)$ and Salix sp. $(\mathrm{D}=0.16, \mathrm{p}<0.01)$ differed the most from the fallow soil under wetting (Fig. 6c) and drying (Fig. 6f) conditions, respectively, in comparison with the other considered woody species. This suggests, in principle, that the former two woody species have a better slope protection performance.

Table 5. Statistical distribution fits for the FoS pool per plant species and hydrological event (i.e. wetting drying). D: statistical distribution; LN: lognormal. a and b: statistical distribution fit coefficients (Standard error range: 0.002-0.003)

\begin{tabular}{|c|c|c|c|c|c|c|}
\hline \multirow{2}{*}{ Plant-species } & \multicolumn{5}{|c|}{ Wetting } & \multicolumn{3}{c|}{ Drying } \\
\cline { 2 - 7 } & $\mathrm{D}$ & $\mathrm{a}$ & $\mathrm{b}$ & $\mathrm{D}$ & $\mathrm{a}$ & $\mathrm{b}$ \\
\hline Acer pseudoplatanus & $\mathrm{LN}$ & 0.34 & 0.82 & $\mathrm{LN}$ & 0.40 & 0.85 \\
\hline Fraxinus excelsior & $\mathrm{LN}$ & 0.35 & 0.82 & $\mathrm{LN}$ & 0.40 & 0.85 \\
\hline Salix sp. & LN & 0.34 & 0.79 & LN & 0.43 & 0.84 \\
\hline Fagus sylvatica & LN & 0.32 & 0.83 & LN & 0.40 & 0.85 \\
\hline Quercus sp. & LN & 0.32 & 0.81 & LN & 0.39 & 0.84 \\
\hline Silene dioica & LN & 0.42 & 0.84 & LN & 0.45 & 0.85 \\
\hline Erigeron acris & LN & 0.45 & 0.83 & LN & 0.45 & 0.85 \\
\hline Fallow soil & LN & 0.19 & 0.74 & LN & 0.23 & 0.73 \\
\hline
\end{tabular}

\subsubsection{Reliability Indices (RIs) and final plant selection}

The RIs (Figs. 7a-h) revealed highly significant differences $\left(\chi^{2}=51.08, \mathrm{df}=7, \mathrm{p}<0.01\right)$ between the tested plant species. In particular, all the studied woody species presented a highly significant positive (stabilising; RI $>0$ ) effect under drying conditions $\left(\chi^{2}=41.76, \mathrm{df}=1, \mathrm{p}<0.01\right)$ with respect to both wetting circumstances and the fallow soil (Figs. 7a-e and 7h). As expected, plant effects were limited to the topmost soil layers (i.e. root zone; 0-0.4 m b.g.1), confirming that vegetation can be effective against shallow landslides and erosion (Stokes et al., 2014; Gonzalez-Ollauri and Mickovski, 2016, 2017a, 2017c). Under drying conditions, Salix sp. presented the greatest positive effect (W=57, $\mathrm{p}<0.01$ ) with respect to the fallow soil, as indicated before (Fig. 6f).

The herbs and fallow soil covers (Figs. 7f-h), however, did not show differences between wetting and drying conditions. This is most likely due to the presence of smaller and shallower root systems (e.g. herbs), or due to their complete absence (e.g. fallow soil). The fact that the RI profiles (Eq.1) for the herbs (Figs. 7f,g) and fallow soil (Fig. 7h) covers did not show values below 0 under wetting conditions does not imply that the slopes under these covers were predicted to be always stable (e.g. see Figs. 6b and 8d-f). The RI profiles (Eq.1, Figs. 7 f-h) were produced as a result of the random selection of a large proportion of low-intensity rainfall events (see supplementary materials) for the simulations carried out. These events did not lead to deep infiltration fronts (i.e. wetting fronts) with the potential of destabilising the evaluated sloped soils compared to what it could be expected for the case of heavy rainfall episodes (e.g. $4 \mathrm{~mm} \mathrm{~h}^{-1}$; Gonzalez-Ollauri and Mickovski, 2017c), or compared 
to what it was predicted for the case of the bypass infiltration derived from stemflow (i.e. assumed to infiltrate the entire soil-root zone) for the woody species (see below). Consequently, FoS values beyond 1.0 were predicted in the topmost horizons for the fallow and herbaceous soil covers under wetting conditions for many model runs. Hence, we recommend the combined usage of the different statistical tools provided within Module V of Plant-Best for a more informed decision on the selection of the of the most adequate plant species. It is also worth noting that detrimental stability conditions were predicted for the fallow soil under drying conditions (Figs. 7h and 8f). The absence of soil cohesion $\left(c^{\prime}=0 \mathrm{kPa}\right)$ assumed herein may be the major cause of this effect (Lu and Godt, 2013).
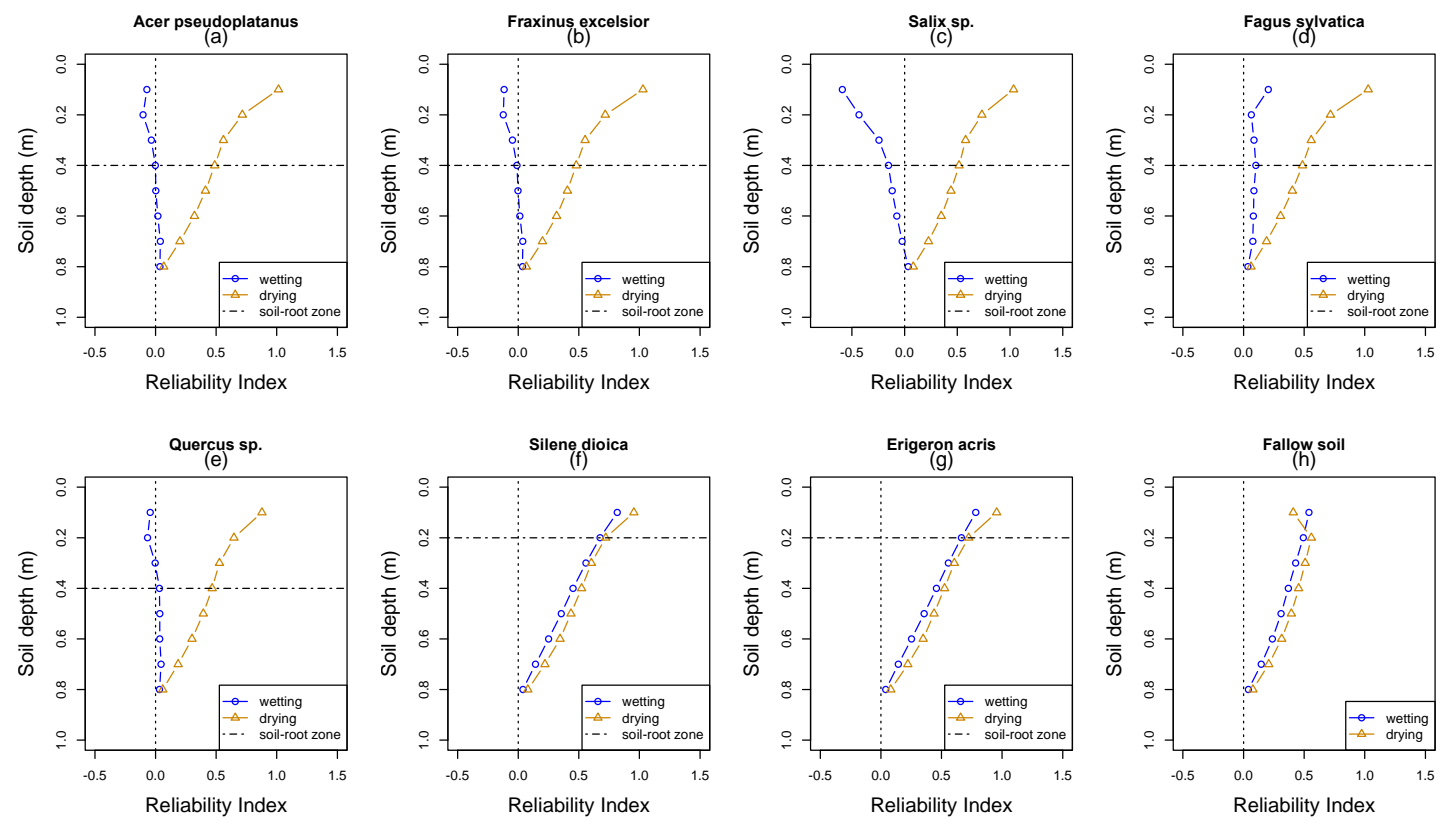

Figure 7. Reliability indices (RIs) for each tested plant cover at different soil depths under wetting and drying conditions. a-e: woody plants; e-g: herbaceous plants; h: fallow soil. RI < 0: reduced instability conditions. Vertical dashed line crossing at $\mathrm{RI}=0$ marks the boundary between improved and reduced slope stability conditions.

For the studied woody species (Section 2.7.2), RIs revealed a reduced stability effect (i.e. $\mathrm{RI}<0$ ) within the topmost soil horizons under wetting conditions (Figs. 7a-e) in almost all cases. Fagus sylvatica (Fig. 7d), along with the herbs (Figs. 7f,g), seemed to be more resilient to the negative response under wetting than the rest of the studied plant species - i.e. under wetting, RI $>0$ (Figs. $7 \mathrm{~d}, \mathrm{f}, \mathrm{g}$ ). The latter suggests that the combination of both types of vegetation covers (i.e. woody and herbaceous; different plant functional groups) could present an adequate solution for better slope protection (e.g. Genet et al., 2010). While herbaceous plants will tend to intercept and store more rainfall (i.e. thick canopy portrayed by the value of $S c$; Table 3), woody plants will provide a deeper and more consistent soil-root mechanical reinforcement (Stokes et al., 2009; Gonzalez-Ollauri and

661 Mickovski, 2016; Tardio et al., 2016). Deeper root systems are related to higher anchorage needs (Stokes et al., 2009), which are, in turn, related to a higher aboveground biomass of the woody (Tardio et al., 2016) with respect to the herbaceous species (Gonzalez-Ollauri and Mickovski, 2016). It is worth 
noting that large structural roots (i.e. diameter $>3.5 \mathrm{~mm}$; structural anchorage roots, sinkers; Stokes et al., 2009) tend to reinforce the soil mechanically through pull-out and stretching mechanisms (Mickovski et al., 2009; Ennos, 1990). Indeed, a greater mechanical reinforcement effect would have been recorded should the contribution of larger woody roots would have been included in Plant-Best (Section 2.3.2). However, the contribution of these mechanisms tends to be relatively smaller than the reinforcement provided by the breakage of smaller non-structural roots (Mickovski et al., 2009). For example, Osman et al. (2011) observed that the pull-out force conferred by entire woody individuals $(1.65-2.25 \mathrm{kN})$ would be comparable to the tensile force provided by 20 to $30,1 \mathrm{~mm}^{2}$ roots.

672 Nonetheless, deeper structural root systems will also lower the soil moisture (i.e. soil stress-state improves) by facilitating drainage within a larger soil zone (Liang et al., 2001; Gonzalez-Ollauri and Mickovski, 2017c).

Two main reasons, or their combination, could have led to the reduced stability effect (i.e. $\mathrm{RI}<0$ ) observed in the RIs (Figs 7a-e) for the woody species under wetting conditions. On the one hand, Plant-Best highlighted the unfavourable effect derived from stemflow (Fig. 3), which is a unique and novel feature of Plant-Best. Stemflow, which was only considered for the woody species, was predicted to concentrate rainwater around the tree stem. This led to the concentration of substantial water volumes dependent on the tree crown area (Ac; Gonzalez-Ollauri and Mickovski, 2017c), despite the low intensity rainfall episodes considered for the simulations. This water volumes were assumed to enter the soil-root zone as a jet (i.e. bypass flow; Liang et al., 2011) without considering the anisotropy of this soil zone, producing negative effects on the soil stress-state that were not counteracted by the estimated root mechanical reinforcement (i.e. excluding pull-out and stretching) or by the cohesionless soil (i.e. c'=0 kPa). Nonetheless, the resilience observed for Fagus sylvatica under wetting conditions (Fig. 7d) was provided by the mechanical reinforcement of a denser root system that, in turn, was derived from a higher predicted plant biomass for this species (i.e. higher mean $D B H$ lead to higher mean $M a$ and, consequently, higher root biomass; Table 3 cont.). This outcome reveals the importance of the soil-root mechanical reinforcement under critical hydrological conditions for an effective slope protection (Gonzalez-Ollauri and Mickovski, 2014). Yet, a denser and more widely spread root system could be also expected to distribute the stemflow volume over a wider ground area with the subsequent reduction of the bypass flow rates per unit volume of ground (Liang et al., 2011; Levia and Germer, 2015). Additionally, the Ac (Table 3) may also play a role in mitigating stemflow effects under real conditions. Albeit the species with a wider crown (Table 3; e.g. Fagus sylvatica) were predicted to concentrate more rainwater around the stem, broader canopies would have the ability of intercepting more rainfall (Deguchi et al., 2006) and would also increase the chances of dripfall (i.e. accumulated rainfall on the tree leaves that eventually falls to the ground; Zimmermann and Zimmermann, 2014). As a result, the water partitioned as stemflow will likely decrease (Llorens and Domingo, 2007) along with the unfavourable effect derived from this mechanism. Anyhow, stemflow will likely be more dependent on the aerial architecture (e.g. stem and branches arrangement; Levia and Germer, 2015;

701 Yuan et al., 2016) than just the Ac. In addition, the infiltration mechanism induced by stemflow needs clarification (Liang et al., 2011; Levia and Germer, 2015). 
On the other hand, the higher plant surcharge provided by woody species could have negative slope stability consequences on steep cohesionless terrain (Lu and Godt, 2013), although this effect is commonly thought to be negligible (Stokes et al., 2008). The possibility of plant surcharge as an instability driver seems to have been captured by Plant-Best when the stemflow effect was suppressed (Fig. 8b) - i.e. there was apparent instability under the woody cover that was not counteracted by the root mechanical reinforcement, and likely caused by the assumed absence of soil cohesion (Gray and Megahan, 1981; Lu and Godt, 2013). However, the evaluation of the slope failure likelihood within the topmost horizons (i.e. $0-0.5 \mathrm{~m}$ b.g.l; Figs. 8a-f) revealed that the main instability driver was the stemflow. This was supported by the consistent improvement of the stability conditions when the stemflow effect was suppressed (Fig. 8b) with respect to the woody cover with stemflow (Fig. 8a), the herbaceous cover (e.g. Silene dioica; Fig. 8d) and the fallow soil (Fig. 8e).

714
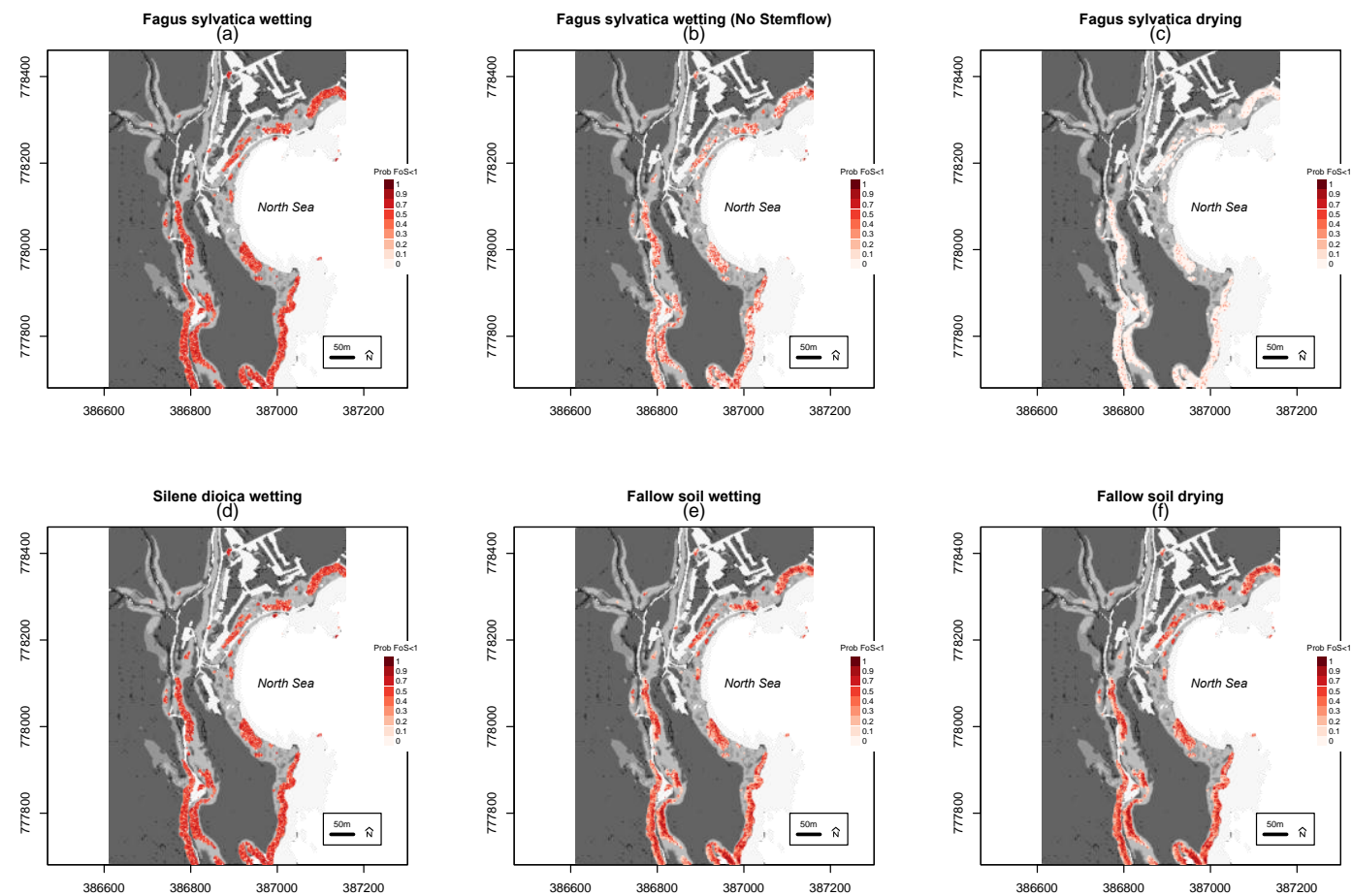

Figure 8. Slope failure likelihood within the topmost soil horizon (i.e. 0-0.5 m) for different plant covers under wetting and drying conditions: (a) Fagus sylvatica under wetting conditions (b) Fagus sylvatica under wetting conditions excluding stemflow effects (c) Fagus sylvatica under drying conditions (d) Silene dioica under wetting conditions (e) Fallow soil under wetting conditions (f) Fallow soil under drying conditions.

The consistent stabilising effect (i.e. RI >>0) predicted for the woody cover under drying conditions (Fig. 8c) is worth being pointed out. This effect was derived from the improvement of the soil stress-state conditions produced by the combination of soil-root mechanical reinforcement, plant transpiration and subsequent reduction of the soil moisture, and corroborates previous research (e.g. Norris et al., 2008; Pollen and Simon, 2010; Gonzalez-Ollauri and Mickovski, 2016, 2017a, 2017c). Nonetheless, it must be borne in mind that the soil reinforcement derived from plant transpiration will be a markedly seasonal process in temperate climates, where the atmospheric demand and, thus, plant transpiration, can be expected to be low during the dormant season (i.e. fall and winter; Wever et al., 
2002). Consequently, it could be expected that only the mechanical effect provided by the vegetation will be effective against landslides under low evapotranspiration conditions.

Overall, Plant-Best outcomes indicated that the combination of Fagus sylvatica with the two tested herbaceous species would lead to a better slope protection performance. Yet, plant species selection with Plant-Best should be harmonised with the ecological evaluation of candidate species for a given slope restoration action (e.g. Evette et al., 2012; Jones, 2013). For the ecological evaluation, aspects such as the origin, life form, growth rate, survival rate, longevity, colonisation requirements or establishment costs of the candidate species should be considered (Stokes et al., 2014). Plant-Best, however, will undoubtedly aid in the final species selection, as it has been shown to be effective for identifying the most geotechnically adequate plant species in a shallow landslides context.

3.3. Sensitive plant traits for soil protection

Plant-Best sensitivity analysis results (SA: Figs. 9a, b) highlighted the robustness of the tool i.e. PV (percentage of variation) < $20 \%$ (e.g. Jackson et al., 2000). The SA outcomes also illustrated which plant traits governed the slope protection outputs. These traits were intimately related to the mechanical and hydrological effects provided by the vegetation on sloped soils.

The most sensitive traits were related to the plant biomass and how this was distributed below ground. Accordingly, the allometric coefficient $\alpha_{a}$ and the $D B H$ were the most sensitive traits (Figs. 9a,b). $\alpha_{a}$ determined the proportion of belowground biomass respect to the aboveground biomass for a given plant species (see Appendix A; Cheng and Niklas, 2007; Gonzalez-Ollauri and Mickovski, 2016). As a result, $\alpha_{a}$ governed indirectly the proportion of rooted soil and, thus, the soil-root mechanical reinforcement. The use of plant allometric coefficients as indicators of plant-derived soil protection has been suggested before (Gonzalez-Ollauri and Mickovski, 2016). However, their quantification may be the hardest of all the inputs required by Plant-Best, as they may necessitate intrusive investigation for their measurement. In this respect, measuring plant allometric relationships using young saplings might be a more suitable alternative to calibrate this parameter (Zianis and Mencuccini, 2004). Still, plants may show plasticity in the relative allocation of biomass between the above and belowground parts (Weiner, 2004) and, hence, allometric changes may occur as a result of forestry management practices (e.g. coppicing; Vergani et al., 2017). With regard to the $D B H$, this was the unique variable that Plant-Best employed for the trees aboveground biomass estimation, provided that it correlates very well with the tree biomass across many woody species (Zianis et al., 2005). Thus, the $D B H$ was directly related to the plant surcharge. More importantly and, given the sensitivity of the allometric relationship between the plants aerial and belowground parts, it becomes evident that the $D B H$ was one of the most sensitive traits. Therefore, $\alpha_{a}$ and $D B H$ could be employed as proxies for the estimation of the root biomass, which, in combination with pedoclimatic and root tensile strength information, could be used to estimate the plant-soil reinforcement (Preti et al., 2010; Gonzalez-Ollauri and Mickovski, 2016) as the crucial characteristic of soil bioengineering design. However, it should be noted that Plant-Best did not consider the effect derived from forestry management practices (e.g. coppicing) on the relative distribution of biomass between the below- and aboveground plant parts or 
(a) Percentage of Variation (PV) Wetting

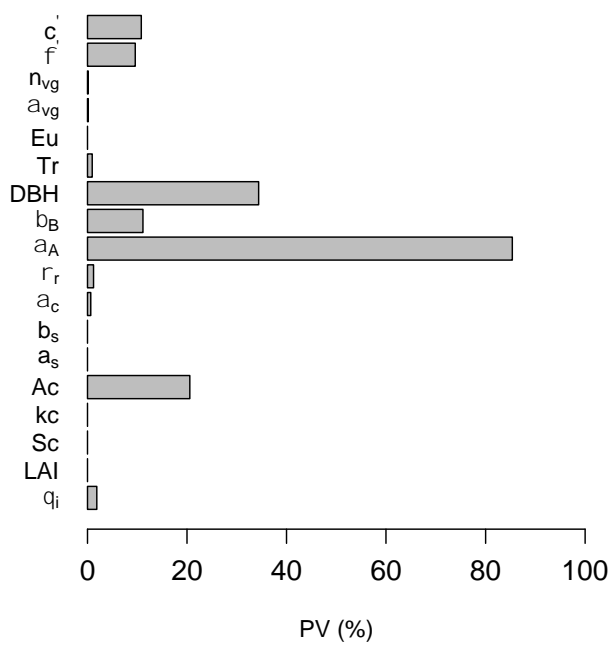

(b) Percentage of Variation (PV) Drying 770

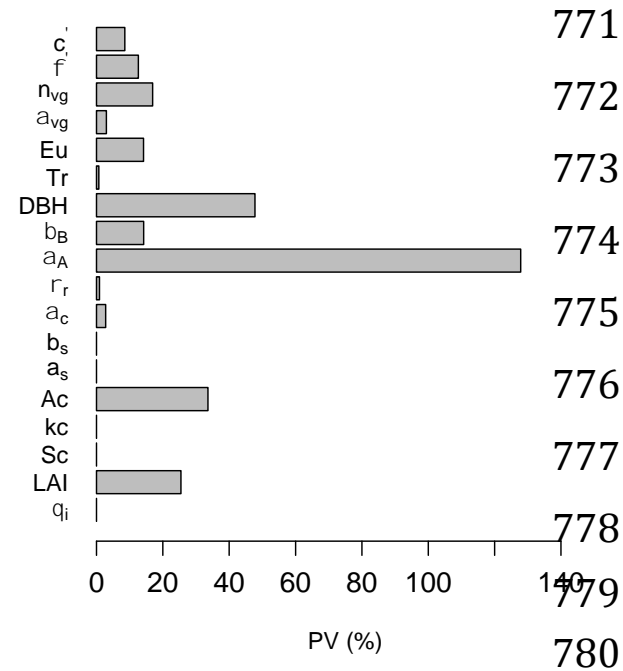

781 Figure 9. Plant-Best sensitivity analysis (SA) outcomes expressed in terms of the percentage of variation (PV) under wetting and drying conditions. The variables presented here are defined in Table 1.

The crown area $(A c)$ appeared to be a sensitive trait (Figs 9a, b), too. Ac had an important role within Plant-Best as a scaling trait for the rainfall interception and stemflow under wetting conditions, as well as for the plant transpiration upon drying (Gonzalez-Ollauri and Mickovski, 2017c). It should be borne in mind that stemflow will more likely depend on the tree aerial architecture (e.g. stem and branches arrangement and morphology; Levia and Germer, 2015) than on the $A c$, although further research on stemflow and its derived effects on slope stability are needed. Thus, and, without considering further ecological interactions (e.g. shading produced by the canopy; Grime, 1977), tree individuals with a wider crown should provide a net positive slope stability effect as they will tend to intercept more rainfall, will distribute the normal load exerted by the plant biomass (i.e. plant surcharge) over a greater area, and will lead to higher net plant transpiration (Caylor et al., 2005). On the basis of these observations, the implementation of pruning practices aiding to shape the canopies in favour of better levels of slope protection could be an interesting possibility to explore. Other sensitive traits were $L A I$ and $n_{v e g}$, which were shown to be sensitive only under drying conditions. With regard to $n_{v e g}$, it is worth noting that plant-derived changes on the soil hydro-mechanical properties are difficult

798 to quantify and are still a major research gap (e.g. Scanlan, 2009; Carminati et al., 2010; GonzalezOllauri and Mickovski, 2017a, 2017c).

It must be borne in mind that $\operatorname{Tr}$ was shown to be non-sensitive trait (Fig. 9). This trait is

801 commonly measured for modelling and estimating the degree of plant-soil mechanical reinforcement 802 (e.g. Stokes et al., 2008, Mickovski et al 2011). Given that the $\operatorname{Tr}$ measures for the tested species (Table 803 3) fell within the range of values reported in the literature (e.g. Bischetti et al., 2005; Stokes et al., 
2008; Burylo et al., 2011), we believe that plant selection for slope protection should focus on different sensitive traits, such as the ones indicated above.

In summary, Plant-Best showed that plants with dense root systems able to confer enough soil-root mechanical reinforcement, with broad and thick canopies that foster high transpiration rates, rainfall interception and dripfall opposed to stemflow were shown to be desirable to enhance slope protection.

\section{CONCLUSION AND FINAL REMARKS}

In the light of the presented outcomes it can be concluded that Plant-Best can be used as a viable tool for the detection of landslide-prone zones, the selection and evaluation of plant covers for

815 slope protection and the identification of relevant plant traits related to shallow landslides mitigation.

816 Plant-Best revealed that different plant species may be suitable for slope protection, depending on the 817 hydrological conditions - i.e. wetting or drying. This suggests that botanically diverse slopes with

818 different plant functional groups are desirable for a more effective soil protection. In general and, from a geotechnical viewpoint, underweight plants with dense root systems and broad thick canopies would

820 perform best against instability. Yet, upon planning actions on slopes that involve the use of plants, we recommend using Plant-Best in combination with the ecological characterisation of potential plant candidates, as slope restoration actions should be carried out in harmony with the environmental features of a particular slope.

Plant-Best has proved to be a holistic, relatively simple, and robust tool that requires a rather low number of measurable inputs for its operation (Table 1). These inputs could also be readily available within online databases (e.g. DAAC, DRYAD, ESDAC, CEDA) and the literature, so one could easily use Plant-Best under any soil, climate or plant conditions. This is possible due to the quantifiable nature of all the parameters involved, and due to the open-source code of Plant-Best (see supplementary materials). For example, users may evaluate the effect of vegetation, or specific meteorological events, on different lithology by simply changing the input value for the soil particle size distribution parameters (i.e. sand, clay, silt content). Seasonal and plant age effects could be also assessed by considering how plant-related parameters vary across seasons (e.g. LAI, Sc) or across

833 developmental stages (e.g. Ac, DBH, Ma). To acknowledge Plant-Best's reliability and value, we

834 encourage its implementation on different and larger sites, under different climatic scenarios, and under different plant covers using species-tailored inputs. Furthermore, the open-source base of Plant-Best

836 confers a great versatility to the tool, where new modules and functions (e.g. lateral flow, perched water tables, soil erosion, coppicing) can be added in and customised depending on the user needs.

838 Future work will include the inclusion of functions portraying the water flow through the soil

839 macropores derived from stemflow, as well as thermal processes and energy balances that include the

840 effects of temperature and sun radiation on the establishment, development and performance of 841 vegetation against landslides overtime.

842 Plant-Best applicability includes, but is not limited to, soil loss estimations, soil water balance assessments, ecosystem services and functions quantification, land-planning, forest management or risk 
assessments at the site and catchment scales. Undoubtedly, Plant-Best is a unique novel tool that opens up an exciting possibility to shed more light on how vegetation can be used effectively in soil bioengineering actions.

Acknowledgment

849 The authors thank the Catterline Brae Action Group (CBAG) for site access and logistical support. We also acknowledge the useful comments from two anonymous reviewers that helped us to enhance the manuscript. This research project was funded by a $\mathrm{PhD}$ scholarship awarded by the School of Engineering and Built Environment of the Glasgow Caledonian University (S1340554).

\section{REFERENCES}

855 Arnone, E., Caracciolo, D., Noto, L. V., Preti, F., Bras, L., 2016. Modelling the hydrological and mechanical effect of roots on shallow landslides. Water Resources Research, 52 (11), 8590 - 8612.

Arnone, E., Dialynas, Y. G., Noto, L. V., Bras, R. L., 2014. Parameter uncertainty in shallow rainfalltriggered landslide modeling at basin scale: a probabilistic approach. Procedia Earth and Planetary Science, 9: 101-111.

Bischetti, G. B., Chiaradia, E. A., Simonato, T., Spexiali, B., Vitali, B., Vullo, P., Zocco, A., 2005. Root strength and root area ratio of forest species in Lombardy (Northern Italy). Plant and Soil, 278 (1): 11-22.

Blozan, W., 2006. Tree measuring guidelines of the Eastern Native Tree Society. Bulletin of the Eastern Native Tree Society. 1 (1), 3-10.

Brèda, N., 2003. Ground-based measurements of leaf area index: a review of methods, instruments and current controversies. Journal of Experimental Botany, 54 (392): 2403-2417.

Breiman, L., 2001. Random forests. Mach. Learn. 45, 5-32.

868 Brooks, R., \& Corey, A., 1964. Hydraulic Properties of Porous Media (Vol. 3). Fort Collins, Colorado: Hydrology Papers-Colorado State University.

BS 1377-2:1990. Methods of test for soils for civil engineering purposes. Classification tests. British Standards Institution. London, UK.

BS 1377-7:1990Methods of test for soils for civil engineering purposes. Classification tests. British Standards Institution. London, UK.

Burylo, M., Hudek, C., Rey, F., 2011. Soil reinforcement by the roots of six dominant species on eroded mountainous marly slopes (Southern Alps, France). Catena 84, 70-78.

876 Carminati, A., Moradi, A.B., Vetterlein, D., Vontobel, P., Lehmann, E., Weller, U., Vogel, H. and Oswald, S.E., 2010. Dynamics of soil water content in the rhizosphere. Plant Soil. 332, 163-176.

878 CEDA, 2017. Centre for Environmental Data Analysis (CEDA). Retrieved on 03/03/2017. http://www.ceda.ac.uk/

Cheng, D., Niklas, K.J., 2007. Above- and below-ground biomass relationships across 1534 forested communities. Ann. Bot. 99, 95-102. 

of the protective function of forests against landslide occurrence: statistical approaches and case study. iForest, 9: 383-393.

Caylor, K.K., Shugart, H. H., and Rodriguez-Iturbe, I. Tree canopy effects on simulated water stress in southern African savannas. Ecosystems, 8: 17-32

DAAC, 2017. NASA Distributed Active Archive Center (DAAC) at NSIDC. Retrieved on 03/03/2017. http://nsidc.org/daac

Daniel, C., 1973. One-at-a-time-plans. J. Am. Stat. Assoc. 68, 353-360.

Deguchi, A., Hattori, S., and Park, H., 2006. The influence of seasonal changes in canopy structure on interception loss: Application of the revised Gash model. Journal of Hydrology. 318, 80-102.

Delignette-Muller, M. L. and Dutang, C., 2014. fitdistrplus: An R package for fitting distributions. Journal of Statistical Software, 64(4), 34 pp.

DRYAD, 2014. Dryad Digital Repository. Retrieved on 03/03/2017. http://datadryad.org/

EEA, 2012. European Environmental Agency (EEA). Soil erosion. Permalink: M2MK6NE2MP

Dexter, A. R., 2004. Soil physical quality Part I. Theory, effects of soil texture, density, and organic matter, and effects on root growth. Geoderma, 120, 201-214.

Efron, B., 1979. Bootstrap methods: another look at the Jackknife. Ann. Statist. 1, $1-26$.

ESDAC, 2017. European Soil Data Centre (ESDAC). European Commission Joint Research Centre. Retrieved on 03/03/2017. http://esdac.jrc.ec.europa.eu/resource-type/datasets

Evans, M.R., Moustakas, A., Carey, G., Malhi, Y., Butt, N., Benham, S., Pallett, D., Schäfer, S., 2015. Data from Allometry and growth of eight tree taxa in United Kingdom woodlands. Scientific Data http://dx.doi.org/10.5061/dryad.2c1s7

Evette, A., Balique, C., Lavaine, C., Rey, F., Prunier, P., 2012. Using ecological and biogeographical features to produce a typology of the plant species used in bioengineering for riverbank protection in Europe. River Res. Appl., 28, 1830-1842.

Félix, R., Xanthoulis, D., 2005. Analyse de sensibilité du modèle mathématique erosion productivity impact calculator (EPIC) par l'approche one-Factor-At-A- time (OAT). Biotechnol. Agron. Soc. Environ. 9 (3), 179-190.

Frattini, P., Crosta, G. and Sosio, R., 2009. Approaches for defining thresholds and return periods for rainfall-triggered shallow landslides. Hydrological Processes, 23: 1444-1460.

Gariano, S. L. and Guzzetti, F., 2016. Landslides in a changing climate. Earth-Science Reviews, 162, 227-252.

Gariano, S. L., Brunetti, M.T., Iovine, G., Melillo, M.,Peruccacci, S., Terranova, O., Vennari, C., Guzzetti, F., 2015. Calibration and validation of rainfall thresholds for shallow landslide forecasting in Sicily, southern Italy. Geomorphology, 228: 653-665.

Genet, M., Stokes, A., Fourcaud, T., Norris, J. E., 2010. The influence of plant diversity on slope stability in a moist evergreen deciduous forest. Ecological Engineering 36: 265-275.

GetMapping, 2014. GetMapping 2 m resolution Digital Surface Model (DSM) for Scotland and Wales. 
Gonzalez-Ollauri, A., Mickovski, S.B., 2014. Integrated model for the hydro-mechanical effects of vegetation against shallow landslides. EQA 13, 35-59.

Gonzalez-Ollauri, A. and Mickovski, S. B., 2015. Hydrological effect of vegetation against shallow landslides: A technical approach. Proceedings of the XVI ECSMGE Geotechnical Engineering for Infrastructure and Development, 1753-1758.

Gonzalez-Ollauri, A. and Mickovski, S. B., 2016. Using the root spread information of pioneer plants to quantify their mitigation potential against shallow landslides and erosion in temperate humid climates. Ecological Engineering, 95: 302-315.

Gonzalez-Ollauri, A. and Mickovski, S. B., 2017a. Plant-soil reinforcement response under different soil hydrological regimes. Geoderma 285, 141-150.

Gonzalez-Ollauri, A. and Mickovski, S. B., 2017b. Shallow landslides as drivers for slope ecosystem evolution and biophysical diversity. Landslides. doi:.1007/s10346-017-0822-y.

Gonzalez-Ollauri, A. and Mickovski, S. B., 2017c. Hydrological effect of vegetation against rainfallinduced landslides. Journal of Hydrology, 549, 374-387.

Gorokhovich, Y., Machado, E. A., Giron Melgar, L. I., Ghahremani, M., 2015. Improving landslide hazard and risk mapping in Guatemala using terrain aspect. Nat Hazards DOI 10.1007/s11069-0152109-8

Gray, D.H. and Megahan, W. F., 1981. Forest vegetation removal and slope stability in the Idaho Batholith. US Department of Agriculture Forest Service, Intermountain Forest and Range Experimental Station Research Paper, INT-271, 1-23.

Grime, J. P., 1977. Evidence for the existence of three primary strategies in plants and its relevance to ecological and evolutionary theory. The American Naturalist, 111(982): 1169-1194.

Haneberg, W. C., 2004. A rational probabilistic method for spatially distributed landslide hazard assessment. Environmental \& Engineering Geoscience, 10 (1): 27-43.

Hazewinkel, M., ed. (2001), "Kolmogorov-Smirnov test", Encyclopedia of Mathematics, Springer, ISBN 978-1-55608-010-4

Head, K. H., 1980. Manual of Soil Laboratory Testing. CRC Press, Boca Raton, US

951 Head, K. H. and Epps, R. J., 2011. Manual of Soil Laboratory Testing: Permeability. Shear Strenght and Compressibility Tests (Vol. 2). CRC Press, Boca Raton, US.

Hughes, S. W., 2005. Archimedes revisited: a faster, better, cheaper method of accurately measuring the volume of small objects. Physics Education, 40(5), 468-474.

Ivanov, V., Bras, R. L., and Vivoni, E. R., 2008a. Vegetation-Hydrology Dynamics in Complex Terrain of Semiarid Areas: II. Energy- Water Controls of Vegetation Spatio-Temporal Dynamics and Topographic Niches of Favorability, Water Resour. Res., 44, W03430

Ivanov, V. Y., Bras, R. L., and Vivoni, E. R., 2008b. Vegetation-Hydrology Dynamics in Complex Terrain of Semiarid Areas: I. A Mechanistic Approach to Modeling Dynamic Feedbacks, Water 
modeling. BioScience, 50(8): 694-706.

Jones, T.A., 2013. Ecologically appropriate plant materials for restoration applications. Bioscience, 63, 211-219.

Kar, S.S. and Ramalingam, A., 2013. Is 30 the magic number? Issues in sample size estimation. National Journal of Community Medicine, 4(1),175-179.

Levia, D. F. and Germer, S., 2015. A review of stemflow generation dynamics and stemflowenvironment interactions in forests and shrublands. Reviews of Geophysics, 53:673-714.

Liang, W., Kosugi, K. and Mizuyama, T., 2011. Soil water dynamics around a tree on a hillslope with or without rainwater supplied by stemflow. Water Resources Research. 47, W02541.

Liaw, A., Wiener, M., 2002. Classification and regression by randomForest. R News 2 (3), 18-22.

Llorens, P. and Domingo, F., 2007. Rainfall partitioning by vegetation under Mediterranean conditions. A review of studies in Europe. Journal of Hydrology, 335, 37-54.

Lu, N. and Likos, W. J., 2004. Unsaturated Soil Mechanics. John Wiley and Sons, Hoboken, US.

Lu, N. and Giffiths, D., 2006. Profiles of steady-state suction stress in unsaturated soils. J. Geotech. Geoenviron. Eng. 130 (10), 1063-1076.

978 Lu, N., Godt, J.W., 2008. Infinite slope stability under steady unsaturated seepage conditions. Water Resources Research. 44, W11404.

980 Lu, N., Godt, J. and Wu, D., 2010. A closed-form equation for effective stress in unsaturated soil. Water Resources Research. 46 (5), 1-14.

Lu, N., and Godt, J., 2013. Hillslope Hydrology and Stability. Cambridge University Press, New York, US.

Malkawi, A. I. H., Hassan, W. F. and Abdulla, F. A., 2000. Uncertainty and reliability analysis applied to slope stability. Structural Safety 22:161-187.

Malone, B., 2013. Use R for Digital Soil Mapping. Soil Security Laboratory, The University of Sidney, Australia.

McBratney, A.B., Mendoça Santos, M.L., Minasny, B., 2003. On digital soil mapping. Geoderma, 117, $3-52$.

Mein, R. and Larson, C., 1973. Modeling infiltration during steady rain. Water Resources Research. 9 (2), 384-394.

Mickovski, S. B., 2014. Resilient design of landslip prevention measures: a case study. Forensic Engineering, 168(2):96-106

Mickovski, S.B., Hallet, P., Bransby, M., Davis, M., Sonnenberg, R., and Bengough, A., 2009. Mechanical Reinforcement of Soil by Willow Roots: Impacts of Roots Properties and Root Failure Mechanisms. Soil Sci. Soc. Am. , 73 (4), 1276-1285.

Mickovski, S. B., Stokes, A., van Beek, L. P. H., Ghestem, M. and Fourcaud, T. 2011. Simulation of direct shear tests on rooted and non-rooted soil using Finite Element analysis. Ecological Engineering, 37 (10): 1523-1532. 
Mickovski, S.B. and Van Beek, L.P.H. 2006. A Decision Support System for the Evaluation of Ecoengineering Strategies for Slope Protection. Geotech Geol Eng 24: 483. doi:10.1007/s10706-0054161-8

Muukkonen, P. and Mäkipää, R., 2006. Biomass equations for European trees: Addendum. Silva Fennica, 40 (4): 763-773.

Neitsch, S., Arnold, J., Kiniry, J., \& Williams, J., 2011. Soil and Water Assessment Tool; Theoretical Documentation. Texas: Water Resources Institute Technical Report No 406.

Norris, J., Stokes, A., Mickovski, S.B., Cameraat, E., Van Beek, R., Nicoll, B., Achim, A., 2008. Slope Stability and Erosion Control: Ecotechnological Solutions. Springer, Doerdrecht, The Netherlands.

Osman, N., Abdullah, M. N., Abdullah, C. H., 2011. Pull-out and tensile strength properties of two selected tropical trees. Sains Malaysiana, 40 (6), 577-585.

Pollen-Bankhead, N. and Simon, A., 2010. Hydrologic and hydraulic effects of riparian root networks on streambank stability: Is mechanical root-reinforcement the whole story? Geomorphology, 116 (3-4): 353-362.

Popova, L., van Dusschoten, D., Nagel, K. A., Fiorani, F., Mazzolai, B., 2016. Plant root tortuosity: an indicator of root path formation in soil with different composition and density. Annals of Botany, 118: 685-698.

Preti, F., 2013. Forest protection and protection forest: Tree root degradation over hydrological shallow landslides triggering. Ecological Engineering, 61P, 633-645.

Preti, F., Dani, A., Laio, F., 2010. Root profile assessment by means of hydrological: pedological and aboveground vegetation information for bio-engineering purposes. Ecol. Eng. 36, 305-316.

Priestley, C., \& Taylor, R. (1972). On the Assessment of Surface Heat Flux and Evaporation Using Large-Scale Parameters. Monthly Weather Review , 100 (2), 81-92.

R Core Team, 2015. R: A language and environment for statistical computing. Viena, Austria: R Foundation for Statistical Computing URL: http://www.R-project.org

Roderick, M.L., Sun, F., Lim, W.H., Farquhar, G.D., 2014. A general framework for understanding the response of the water cycle to global warming over land and ocean. Hydrology and Earth System Sciences, 18(5), 1575-1589.

Ross, S. M., 2006. Simulation. $4^{\text {th }}$ Ed. Elsevier, Amsterdam, The Netherlands.

Savabi, M.R. and Williams, J.R., 1995. Water balance and percolation. In Flanagan, D.C. and Nearing, M.A. (eds.), USDA-Water Erosion Prediction Project: Hillslope and watershed model documentation. NSERL Report No. 10. USDA-ARS National Soil Erosion Research Laboratory, West Lafayette, US.

Saxton, K., \& Rawls, W., 2006. Soil Water Characteristic Estimates by Texture and Organic Matter for Hydrologic Solutions. Soil Sci. Soc. Am. J. , 70, 1569-1578.

Scanlan, C.A., 2009. Porcesses and effects of root-induced changes to soil hydraulic properties. $\mathrm{PhD}$ Thesis, University of Western Australia.

Schiliro, L., Montraiso, L., Mugnozza, G. S., 2016. Prediction of shallow landslide occurrence: Validation of a physically-based approach through a real case study. Science of the Total Environment, 569-570: 134-144. 
Schindler, U. \& Muller, L., 2006. Simplifying the evaporation method for quantifying soil hydraulic properties. J. Plant. Nutr. Soil Sci. 169, 623-629.

Schulte, E. and Hopkins, B.G., 1996. Estimation of soil organic matter by weight loss-on-ignition. In Magdoff, F. et al. Soil Organic Matter: Analysis and Interpretation. Soil Sci. Soc. Am., Madison, US, pp. 21-31.

Schwilch, G., Bernet, L., Fleskens, L., Giannakis, E., Leventon, J., Marañon, T., Mills, J., Short, C., Stolte, J., van Delden, H., Verzandvoort, S., 2016. Operationalizing ecosystem services for the mitigation of soil threats: A proposed framework. Ecological Indicators, 67:586-597.

Scurlock, J. M. O., Asmer, G. P. and Gower, S. T., 2001. Worldwide historical estimates of leaf area index, 1932-2000. US Department of Energy, 44 pp. https://daac.ornl.gov/VEGETATION/lai_des.html

Sidle, R. C. and Bogaard, T. A., 2016. Dynamic earth system and ecological controls of rainfallinitiated landslides. Earth-Science Reviews, 159:275-291.

Stokes, A., Norris, J., van Beek, L., Bogaard, T., Cammeraat, E., Mickovski, S.B. et al. (2008) How vegetation reinforces soil on slopes. In: Norris, J, Stokes, A, Mickovski, S. B., Cameraat, E., Van Beek, R., Nicoll, B., Achim, A., 2008. Slope Stability and Erosion Control: Ecotechnological Solutions (pp. 65-116). Springer, Doerdrecht, The Netherlands.

Stokes A., Atger C., Bengough A.G., Fourcaud T., Sidle R.C., 2009. Desirable plant root traits for protecting natural and engineered slopes against landslides. Plant and Soil, 324 (1) : p. 1-30.

Stokes, A., Douglas, G., Fourcaud, T., Giadrossich, F., Gillies, C., Hubble, T., et al., 2014. Ecological mitigation of hillslope instability: ten key issues facing researchers and practitioners. Plant Soil , $377,1-23$.

Tardio, G., Gonzalez-Ollauri, A. and Mickovski, S. B., 2016. A non-invasive root distribution analysis methodology from a slope stability approach. Ecological Engineering, 97: 46-57.

Toth, B., Weynants, M., Nemes, A., Mako, A., Bilas, G., Toth, G., 2015. New generation of hydraulic pedotransfer functions for Europe. Eur. J. Soil Sci. 66, 226-238.

UK Met Office, 2015. MIDAS Land Surface Stations data, 1853-current. Retrieved from http://badc.nerc.ac.uk/view/badc.nerc.ac.uk_ATOM_dataent_ukmo-midas.

USDA-NRCS (1997) National Grazing Lands Handbook. USDA-NRCS, Washington DC, US.

van Genuchten, M., 1980. A closed-form equation predicting hydraulic conductivity of unsaturated soils. Soil Sci. Soc. Am. J. 44, 892-898.

van Westen, C. J., van Asch. T. W. J. and Soeters, R., 2006. Landslide hazard and risk zonation - why is it so difficult? Bull Eng Geol Env, 65: 167-184.

Vergani, C., Giadrossich, F., Schwarz, M., Buckley, P., Conedera, M., Pividori, M., Salbitano, F., Rauch, H.S., Lovreglio, R., 2017. Root reinforcement dynamics of European coppice woodlands and their effect on shallow landslides: A review. Earth-Science Reviews, 167, 88-102. doi: 10.1016/j.earscirev.2017.02.002

Vorpahl, P., Elsenbeer, H., Marker, M., Schroder, B., 2012. How can statistical models help to determine driving factors of landslides? Ecological Modelling, 239: 27-39. 
Weiner, J., 2004. Allocation, plasticity and allometry in plants. Perspectives in Plant Ecology, Evolution and Systematics, 6/4, 207-2017.

1081 Wever, L.A., Flanagan, L.B., Carlson, P.J., 2002. Seasonal and interannual variation in evapotranspiration, energy balance and surface conductance in a northern temperate grassland. Agricultural and Forest Meteorology, 112, 31-49.

White, B., Ogilvie, J., Campbell, D. M. H., Hiltz, D., Gauthier, B., Chisholm, H. K. H., Wen, H. K., Murphy, N. C. and Arp, P. A., 2012. Using the cartographic Depth-to-Water Index to locate small streams and associated wet areas across landscapes. Canadian Water Resources Journal, 37(4):333347.

Wilkinson, P. L., Anderson, M. G. and Lloyd, D. M., 2002. An integrated hydrological model for raininduced landslide prediction.

Wolf, D., Carson, E.A. and Brown, R.H., 1972. Leaf Area Index and Specific Leaf Area determinations. Jour. of Agron. Educ. 1, 24-27.

Wu, H., McKinnell, W., Swanston, D., 1979. Strength of tree roots and landslides on Prince of Wales Island, Alaska. Can. Geotech. J. 16 (1), 19-33.

Wu, W., ed., 2015. Recent advances in modelling landslides and debris flows. Springer Series in Geomechanics and Geoengineering. Springer, Switzerland

Yuan, C., Gao, G. and Fu, B., 2016. Stemflow of a xerophytic shrub (Salix psammophila) in northern China: Implication for beneficial branch architecture to produce stemflow. Journal of Hydrology, 539: 577-588.

Zianis, D. and Mencuccini, M., 2004. On simplifying allometric analysis of forest biomass. Forest Ecology and Management, 187: 311-332.

Zianis, D., Muukkonen, P., Mäkipää, R., Mencuccini, M., 2005. Biomass and stem volume equations for tree species in Europe. Silva Fennica Monographs, 4: 63 pp

1103 Zimmermann, A. and Zimmermann, B., 2014. Requirements for throughfall monitoring: The roles of temporal scale and canopy complexity. Agricultural and Forest Meteorology, 189-190, 125-139. 


\begin{tabular}{|c|c|c|c|c|}
\hline Sub-model & No & Equation & Variable & Sources \\
\hline Stems number & Eq.1 & $N_{\text {stems }}=L P A / m A c$ & $\begin{array}{l}\text { Nstems: number of stems } \\
\text { LPA: landslide-prone area } \\
\left(\mathrm{m}^{2}\right) \\
\text { mAc: mean tree-crown area } \\
\left(\mathrm{m}^{2}\right)\end{array}$ & \\
\hline \multirow[t]{4}{*}{ Tree biomass } & Eq. 2 & Acer pseudoplatanus: $\ln M a=-2.70+2.57 \ln D B H$ & $\begin{array}{l}\text { Ma: aboveground biomass } \\
\left(\mathrm{kg}^{-1} \mathrm{tre}^{-1}\right)\end{array}$ & $\begin{array}{l}\text { Zianis et al. } \\
(2005)\end{array}$ \\
\hline & Eq.4 & $\begin{aligned} & \text { Salix sp.: } M a= M b r+M f l+M s t \\
& M b r=\exp (2.47+2.50 \ln D B H) \\
& M f l=\exp (1.47+2.31 \ln D B H) \\
& M s t=\exp \left(4.51+1.92 \ln D B H+0.26[\ln D B H]^{2}\right)\end{aligned}$ & $\begin{array}{l}\text { Mbr: branch biomass }(\mathrm{kg} \\
\text { tree } \\
\text { Mfl: foliage biomass }(\mathrm{kg} \\
\text { tree }^{-1} \text { ) } \\
\text { Mst: stem biomass ( } \mathrm{kg} \text { tree } \\
{ }_{1} \text { ) }\end{array}$ & $\begin{array}{l}\text { Mukkonen and } \\
\text { Makipaa (2006) }\end{array}$ \\
\hline & Eq. 5 & Fagus sylvatica: $M a=0.08 D B H^{2.60}$ & & $\begin{array}{l}\text { Zianis et al. } \\
(2005)\end{array}$ \\
\hline & Eq. 8 & $M a=\beta a M r^{\alpha a}$ & $\begin{array}{l}\text { Mr: belowground biomass } \\
\left(\mathrm{kg} \text { tree }{ }^{-1}\right) \\
\beta_{\mathrm{a}}: \text { allometric coefficient } \\
\alpha_{\mathrm{a}}: \text { allometric exponent }\end{array}$ & $\begin{array}{l}\text { Cheng and } \\
\text { Niklas (2007) }\end{array}$ \\
\hline Root spread & Eq.9 & $\operatorname{Ar}(z)=\operatorname{Aro} \exp (-b z)$ & $\begin{array}{l}\text { Ar: root cross-sectional } \\
\text { area }\left(\mathrm{mm}^{2}\right)\end{array}$ & $\begin{array}{l}\text { Preti et al. } \\
(2010)\end{array}$ \\
\hline
\end{tabular}




\begin{tabular}{|c|c|c|c|c|}
\hline Sub-model & No & Equation & Variable & Sources \\
\hline \multirow[t]{3}{*}{ Root spread } & Eq.10 & $A r_{o}=M r / b \rho r$ & $\begin{array}{l}\mathrm{Ar}_{\mathrm{o}} \text { : root cross-sectional } \\
\text { area at ground surface } \\
\left(\mathrm{mm}^{2}\right)\end{array}$ & \\
\hline & & & $\begin{array}{l}\alpha_{\mathrm{c}} \text { : mean rainfall intensity } \\
\text { during growing season }(\mathrm{mm} \\
\mathrm{H}_{2} \mathrm{O} \text { event }{ }^{-1} \text { ) } \\
\mathrm{n} \text { : soil porosity } \\
\theta \mathrm{fc} \text { : volumetric moisture } \\
\text { content at field capacity } \\
\theta \mathrm{wp} \text { : volumetric moisture } \\
\text { content at wilting point } \\
\lambda_{\mathrm{o}} \text { : rainfall frequency } \\
\text { during growing season } \\
\text { Etp: mean daily } \\
\text { evapotranspiration rate } \\
\text { during growing season }(\mathrm{mm} \\
\left.\mathrm{H}_{2} \mathrm{O} \text { day }^{-1}\right)\end{array}$ & \\
\hline & Eq.13 & $R A R(z)=\operatorname{Ar}(z) / P x$ & $\begin{array}{l}\text { RAR: root area ratio } \\
\text { Px: pixel resolution }\left(\mathrm{mm}^{2}\right)\end{array}$ & This study \\
\hline $\begin{array}{l}\text { Rainfall } \\
\text { interception }\end{array}$ & Eq.14 & $E R=P g-(S / c) A c^{\prime}$ & $\begin{array}{l}\text { ER: effective rainfall ( } \mathrm{mm} \\
\mathrm{H}_{2} \mathrm{O} \text { ) }\end{array}$ & This study \\
\hline
\end{tabular}




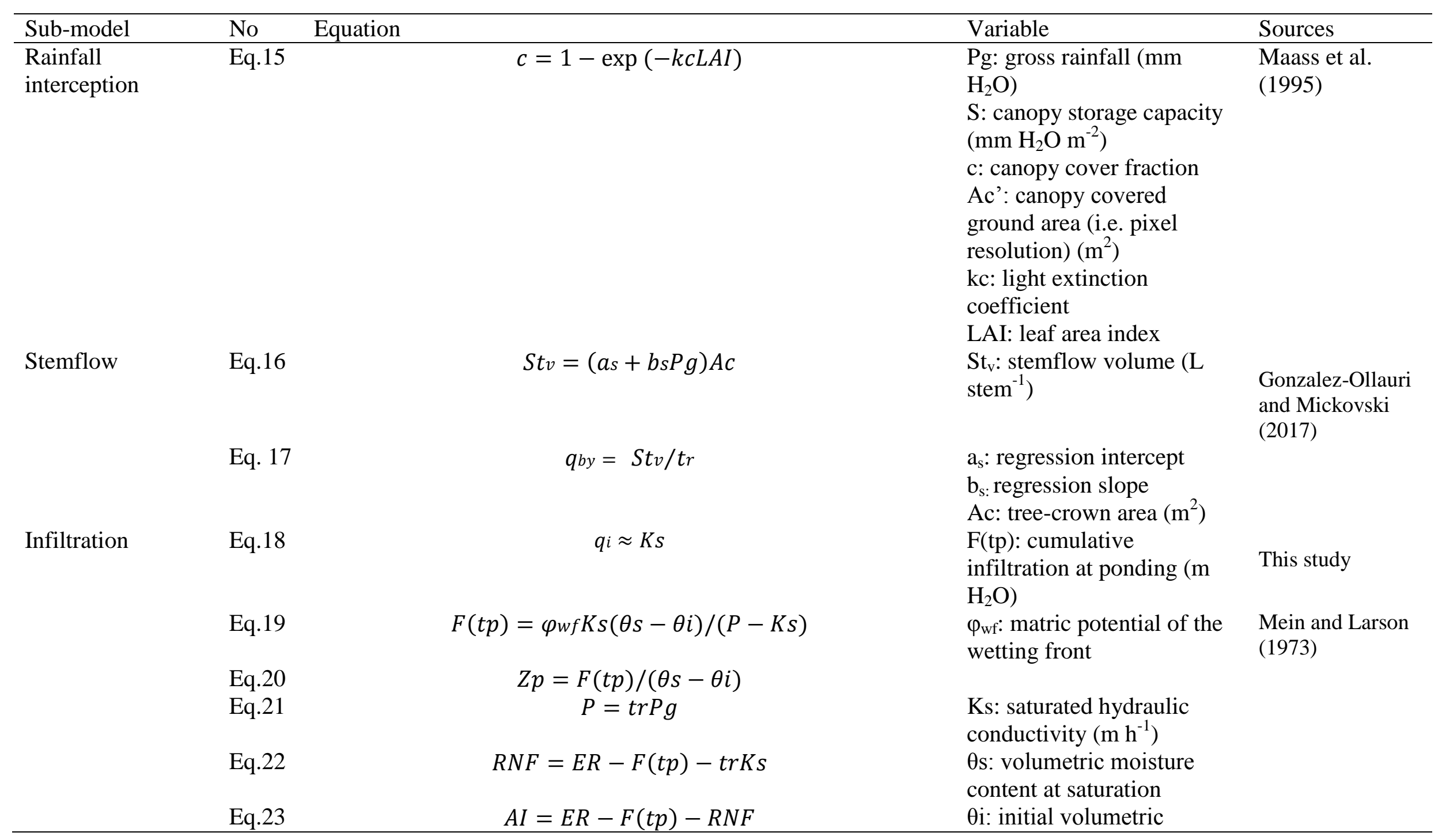




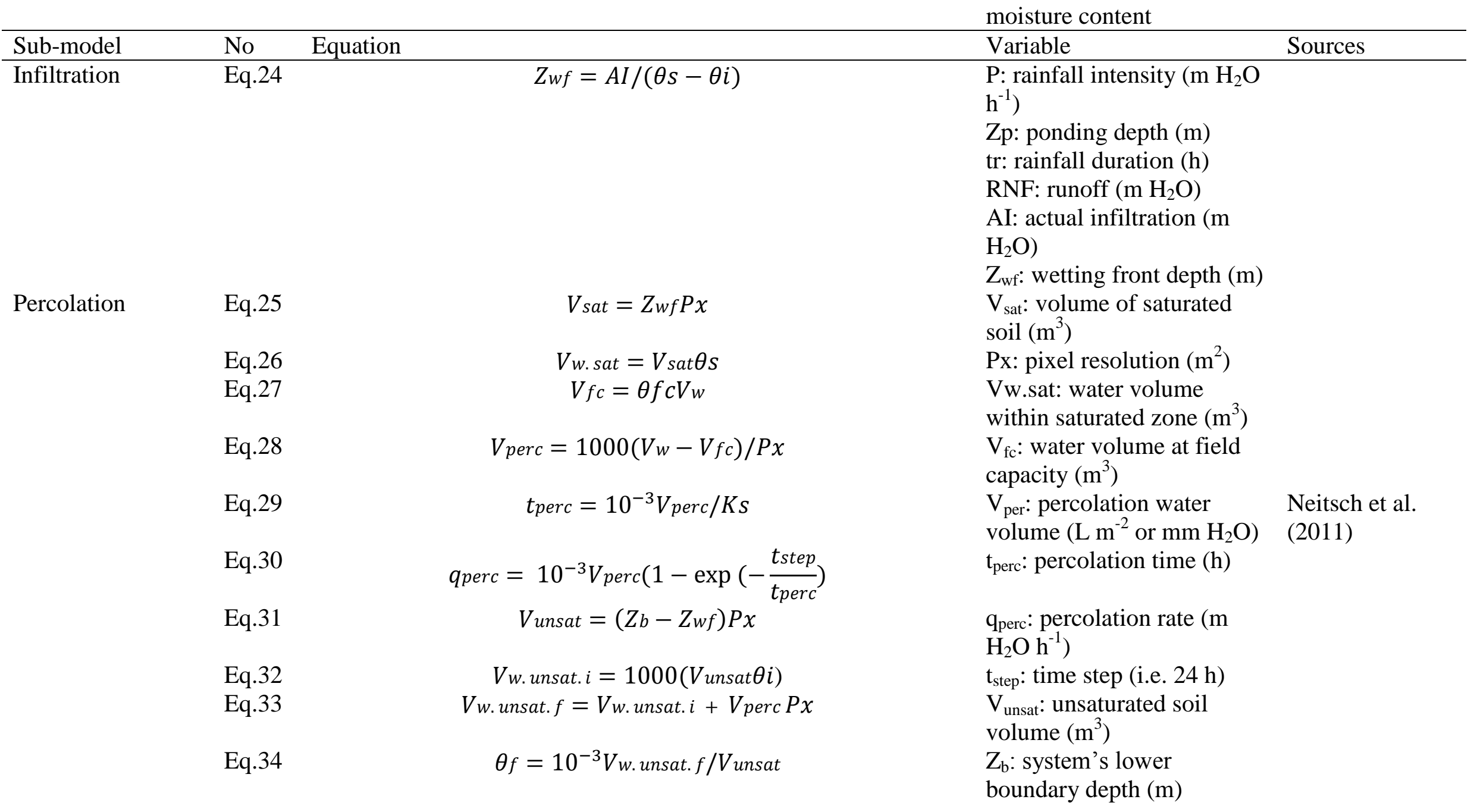




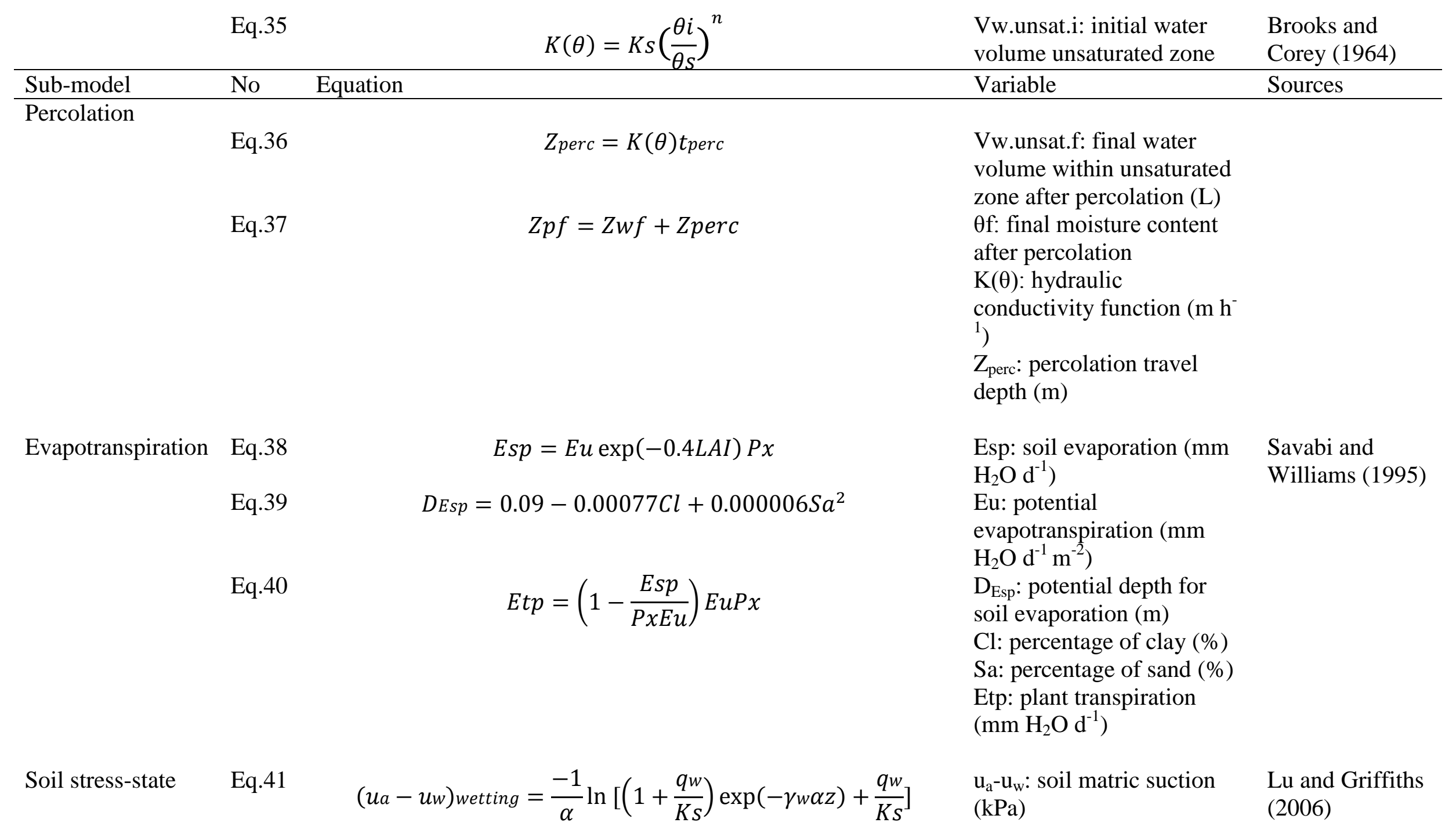




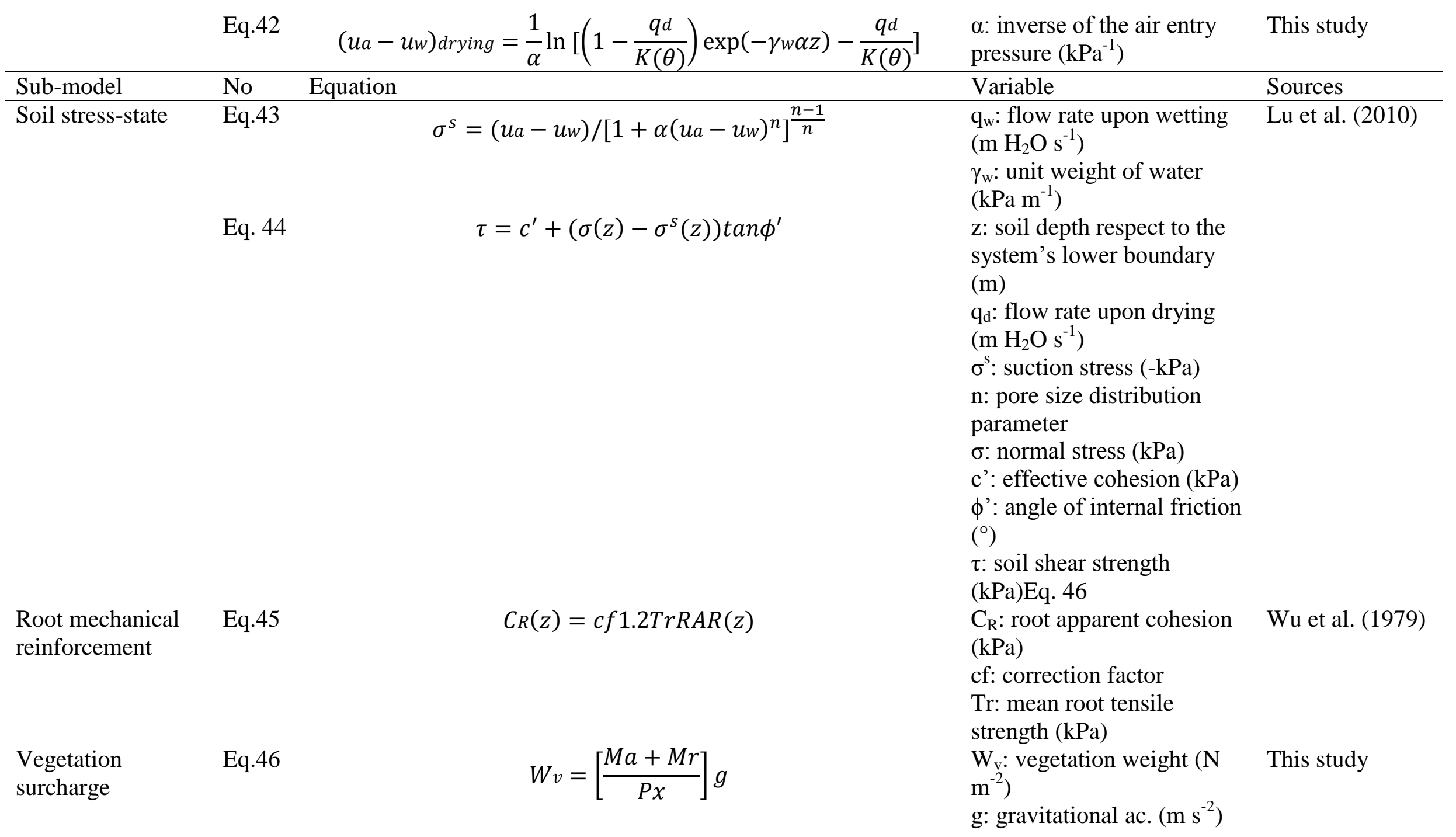




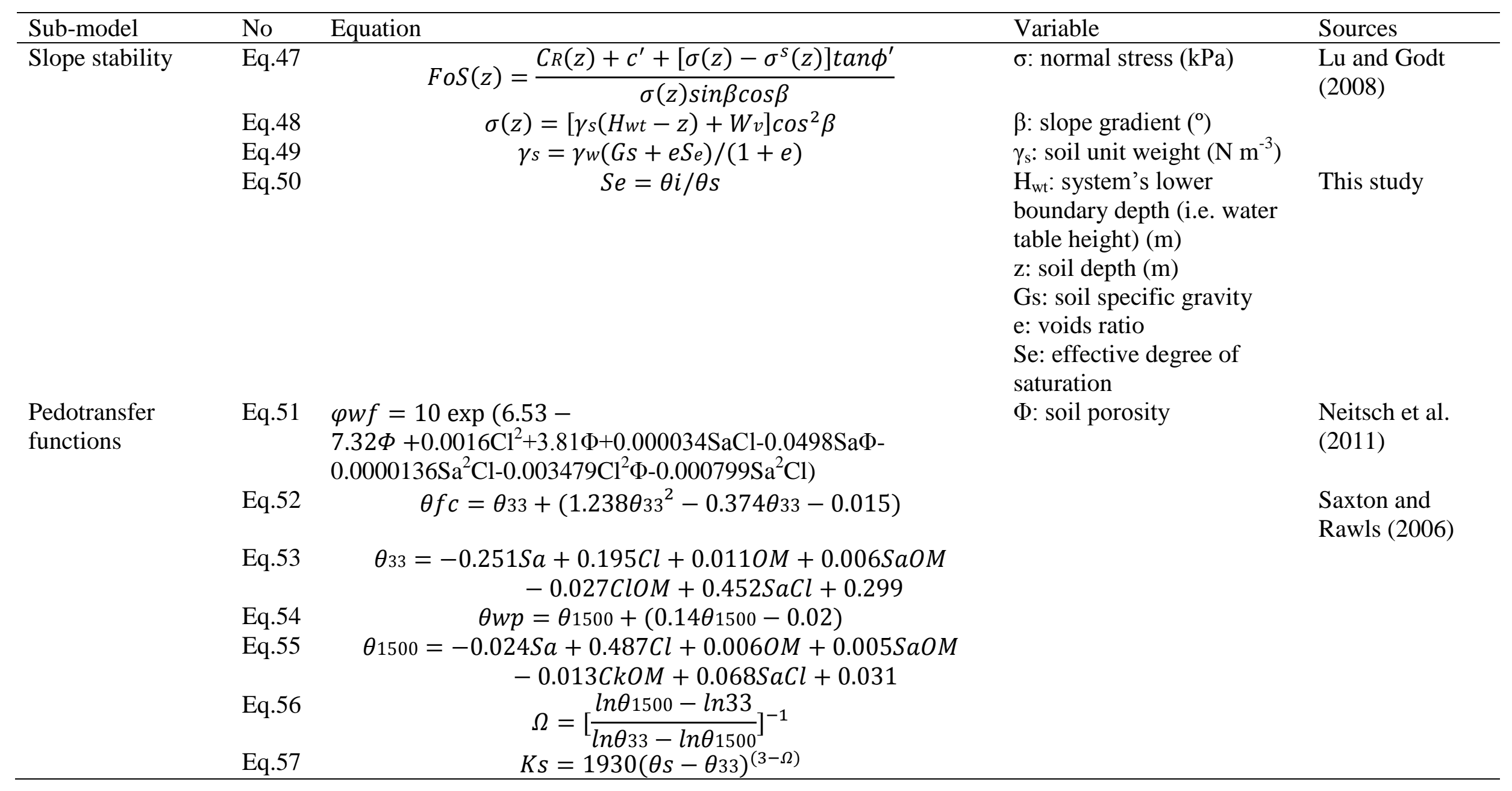


APPENDIX A: MODULE II EQUATIONS

1109 


\section{REFERENCES}

Brooks, R., \& Corey, A., 1964. Hydraulic Properties of Porous Media (Vol. 3). Fort Collins, Colorado: Hydrology Papers-Colorado State University.

Cheng, D., Niklas, K.J., 2007. Above- and below-ground biomass relationships across 1534 forested communities. Ann. Bot. 99, 95-102.

Gonzalez-Ollauri, A. and Mickovski, S. B., 2016. Using the root spread information of pioneer plants to quantify their mitigation potential against shallow landslides and erosion in temperate humid climates. Ecological Engineering, 95: 302-315.

Gonzalez-Ollauri, A. and Mickovski, S. B., 2017. Hydrological effect of vegetation against rainfallinduced landslides. Journal of Hydrology, 549, 374-387.

Laio, F., D’Odorico, P., Ridolfi, L., 2006. An analystical model to relate the vertical root distribution to climate and soil properties. Geophys. Res. Lett. 33, L18401.

Lu, N. and Giffiths, D., 2006. Profiles of steady-state suction stress in unsaturated soils. J. Geotech. Geoenviron. Eng. 130 (10), 1063-1076.

Lu, N., Godt, J.W., 2008. Infinite slope stability under steady unsaturated seepage conditions. Water Resources Research. 44, W11404.

Lu, N., Godt, J. and Wu, D., 2010. A closed-form equation for effective stress in unsaturated soil. Water Resources Research. 46 (5), 1-14.

Maass,J.M.,Vose,J.M.,Swank,W.T.,Martınez-Yrızar,A.,1995. Seasonal changes of leaf area index

(LAI) in a tropical deciduous forest in west Mexico. Forest Ecology and Manage- ment 74, 171-180.

Mein, R. and Larson, C., 1973. Modeling infiltration during steady rain. Water Resources Research. 9 (2), 384-394.

Muukkonen, P. and Mäkipää, R., 2006. Biomass equations for European trees: Addendum. Silva Fennica, 40 (4): 763-773.

Neitsch, S., Arnold, J., Kiniry, J., \& Williams, J., 2011. Soil and Water Assessment Tool; Theoretical Documentation. Texas: Water Resources Institute Technical Report No 406.

Preti, F., Dani, A., Laio, F., 2010. Root profile assessment by means of hydrological: pedological and aboveground vegetation information for bio-engineering purposes. Ecol. Eng. 36, 305-316.

Savabi, M.R., Engman, E.T., Kustas, W.P., Rawls, W.J. and Kenemasu, E.T., 1989. Water balance and percolation. In L. a. Lane, USDA-Water Erosion Prediction Project: Hillslope Profile Model Documentation (Vol. Chapter 7). USDA-ARS National Soil Erosion Research Laboratory, West Lafayette, US.

Saxton, K., \& Rawls, W., 2006. Soil Water Characteristic Estimates by Texture and Organic Matter for Hydrologic Solutions. Soil Sci. Soc. Am. J. , 70, 1569-1578.

Wu, H., McKinnell, W., Swanston, D., 1979. Strength of tree roots and landslides on Prince of Wales Island, Alaska. Can. Geotech. J. 16 (1), 19-33.

Zianis, D., Muukkonen, P., Mäkipää, R., Mencuccini, M., 2005. Biomass and stem volume equations for tree species in Europe. Silva Fennica Monographs, 4: 63 pp 
APPENDIX B: MODULE II ASSUMPTIONS

\begin{tabular}{|c|c|}
\hline Sub-model & Assumptions \\
\hline Stem number & Trees in adult state \\
\hline \multirow[t]{5}{*}{ Root spread } & Root system follows a negative exponential decrease with soil depth \\
\hline & Steady-sate mature vegetation \\
\hline & Water is the limiting resource \\
\hline & Isotropic soil conditions \\
\hline & Belowground biomass estimated with allometric model \\
\hline \multirow[t]{4}{*}{ Rainfall interception } & Rainfall occurs as a series of discrete events \\
\hline & Litter interception negligible \\
\hline & All throughfall is eligible to infiltrate into the soil \\
\hline & Dripfall is pooled within the throughfall estimate \\
\hline Stemflow & All the tree crown collects water for stemflow \\
\hline \multirow[t]{11}{*}{ Infiltration } & Isotropic soil \\
\hline & Soil moisture is uniformly distributed throughout the soil profile \\
\hline & Rainfall is steady \\
\hline & Wetting front saturates the soil behind \\
\hline & Wetting front is at constant head \\
\hline & If ponding does not form, all rainfall infiltrates \\
\hline & Wetting front stops when rain ceases \\
\hline & After ponding, infiltration rate approaches Ks \\
\hline & In principle, all rainfall is eligible to infiltrate \\
\hline & All non-infiltrated rainfall runoffs \\
\hline & Runoff does not infiltrate elsewhere (i.e. exists the system) \\
\hline \multirow[t]{10}{*}{ Percolation } & Instantaneous percolation once rain stops \\
\hline & Lateral and preferential flow neglected \\
\hline & Percolation occurs as a piston flow \\
\hline & Isotropic soil \\
\hline & Uniform moisture content below the wetting front \\
\hline & Excess water is all the volume exceeding field capacity \\
\hline & All excess water percolates \\
\hline & Steady percolation rate \\
\hline & $\begin{array}{l}\text { Travel distance approximated with HCF (Eq. 38) at the final } \\
\text { moisture content }\end{array}$ \\
\hline & Beyond percolation front, hydrostatic conditions hold \\
\hline \multirow[t]{3}{*}{ Evapotranspiration } & Assumptions from Priestly and Taylor (1972) apply \\
\hline & Same transpiration rate within the root zone \\
\hline & Soil evaporation is limited to a depth determined by the soil type \\
\hline \multirow[t]{3}{*}{ Soil stress-state } & Isotropic soil \\
\hline & Steady-state infiltration, percolation and evapotranspiration \\
\hline & If matric suction is below or equal to 0 , saturated conditions hold \\
\hline
\end{tabular}


APPENDIX B: MODULE II ASSUMPTIONS

\begin{tabular}{|c|c|}
\hline Sub-model & Assumptions \\
\hline & Under saturated conditions, suction stress is equal to 0 \\
\hline & Soil hysteresis neglected \\
\hline & Pore-size distribution parameter changes when soil is vegetated (i.e. \\
\hline & 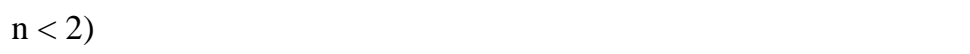 \\
\hline \multirow{3}{*}{$\begin{array}{l}\text { Root } \\
\text { reinforcement }\end{array}$} & Roots perpendicular to the shear plane \\
\hline & At failure all roots break \\
\hline & Only fine roots (i.e. smaller than $3.5 \mathrm{~mm}$ in diameter) are considered \\
\hline Vegetation surcharge & Above and belowground biomass surcharge is considered together \\
\hline \multirow[t]{6}{*}{ Slope stability } & Infinite slope \\
\hline & Isotropic soil \\
\hline & Slope is at its limit equilibrium \\
\hline & Water table is the lowest boundary and it is static \\
\hline & Hydrological steady-state conditions \\
\hline & Effective degree of saturation calculation is simplified \\
\hline
\end{tabular}


Table C.1. Soil spatial variables (SSVs) prediction outcomes obtained from implementing RF algorithms. $\mathrm{R}^{2}$ : coefficient of determination; RMSE: residual mean square error. The rest of the cells show the variable importance (\%) for the prediction of a given SSV. Sn: sand content; St: silt content; Cl: clay content; SOM: soil organic matter; $\Phi$ : soil porosity.

\begin{tabular}{|l|l|l|l|l|l|l|l|l|l|l|}
\hline SSV & $\mathrm{R}^{2}$ & RMSE & VE (\%) & Slope & Aspect & Curvature & $\begin{array}{l}\text { Land } \\
\text { Cover }\end{array}$ & Sn & Cl & OM \\
\hline Sn & 0.86 & 16.14 & 43.8 & 19.41 & 5.68 & -7.01 & 29.69 & & & \\
\hline St & 0.96 & 67.17 & 74.13 & 12.48 & 3.83 & -1.60 & 10.62 & 41.98 & & \\
\hline Cl & 0.97 & 63.01 & 82.34 & 17.81 & 8.83 & -0.04 & 15.48 & 39.14 & & \\
\hline SOM & 0.83 & 61.01 & 48.07 & 8.18 & -1.54 & 0.71 & 24.059 & 17.10 & 13.23 & \\
\hline$\Phi$ & 0.96 & 61.07 & 87.07 & 6.08 & 2.02 & -3.86 & 10.28 & 19.78 & 17.83 & 19.50 \\
\hline
\end{tabular}

